\title{
Nuclear fuels and development of nuclear fuel elements*
}

\author{
C V SUNDARAM and S L MANNAN
}

Indira Gandhi Centre for Atomic Research, Kalpakkam 603 102, India

MS received 6 April 1989

\begin{abstract}
The importance of nuclear energy in meeting future energy demands has been well-recognised and a variety of nuclear reactor systems have been developed. Inherent characteristics of nuclear technology like neutron economy and neutron irradiation-induced degradation in properties of materials require stringent control of material purity and necessarily limit the choice of candidate materials. Hence safe, reliable and economic operation of nuclear fission reactors, the source of nuclear power at present, requires judicious choice, careful preparation and specialised fabrication procedures for fuels and fuel element structural materials. These aspects of nuclear fuels (uranium, plutonium and their oxides and carbides), fuel element technology and structural materials (aluminium, zircaloy, stainless steel etc.) are discussed with particular reference to research and power reactors in India, e.g. the DHRUVA research reactor at BARC, Trombay, the pressurised heavy water reactors (PHWR) at Rajasthan and Kalpakkam, and the Fast Breeder Test Reactor (FBTR) at Kalpakkam. Other reactors like the gas-cooled reactors operating in UK are also mentioned. Because of the limited uranium resources, India has opted for a three-stage nuclear power programme aimed at the ultimate utilization of her abundant thorium resources. The first phase consists of natural uranium dioxide-fuelled, heavy water-moderated and cooled PHWR. The second phase was initiated with the attainment of criticality in the FBTR at Kalpakkam. Fast Breeder Reactors (FBR) utilize the plutonium and uranium by-products of phase 1 . Moreover, FBR can convert thorium into fissile U-233. They produce more fuel than is consumed - hence, the name breeders. The fuel parameters of some of the operating or proposed fast reactors in the world are compared. FBTR is unique in the choice of mixed carbides of plutonium and uranium as fuel. Factors affecting the fuel element performance and life in various reactors e.g. hydriding of zircaloys, fuel pellet-cladding interaction etc. in PHWR and void swelling, irradiation creep and helium embrittlement of fuel element structural materials in FBR are discussed along with measures to overcome some of these problems.
\end{abstract}

Keywords. Nuclear fuel; fuel element; zircaloy; void swelling; irradiation damage; pellet-clad interaction.

\footnotetext{
* Lecture presented at the Frontier Symposium of the Engineering Sciences Session of the 75th Indian
} Science Congress, Pune, January 9, 1988 


\section{Introduction}

A nuclear reactor is basically a source of heat in which energy is released through the fission of an isotope of uranium or plutonium. Uranium-235, which constitutes about $\mathbf{0 . 7 \%}$ of naturally occurring uranium, is the primary fissile material for fuelling nuclear reactors. Plutonium-239 and U-233, on the other hand, are synthetic fuels produced by 'transmutations respectively of fertile nuclides U-238 and Th-232. The first reactor in the world which produced electricity was the experimental breeder reactor (FBR-I) in USA in 1951. Since then, a large number of nuclear reactors have been built both for research purposes and the generation of electricity. Because of the limited availability of coal, oil, gas and hydro resources, the need to develop alternative sources of energy has been well-recognized. Past and likely future patterns of energy consumption, as suggested in figure 1 (Rippon 1984, pp. 1-20) indicate that the development of nuclear reactors is of paramount importance for meeting future energy demands. Advantage in the use of nuclear energy also arises from the fact that far more electricity can be produced from lesser quantities of natural resources than from any other established source of energy (table 1).

\subsection{Types of reactors}

In order to sustain a fission chain reaction in natural uranium or low-enrichment uranium, it is necessary to reduce the energy of the fission neutrons (which are born with a spectrum of energies around $2 \mathrm{MeV}$ ) by means of scattering collisions with suitable light moderator atoms, till the neutrons attain low enough energies (around $0.025 \mathrm{eV}$ ) at which they are in thermal equilibrium with matter. Such reactors are called thermal reactors. The typical moderators used in such thermal reactors are water, heavy water and graphite. If the chain reaction is to be sustained without a

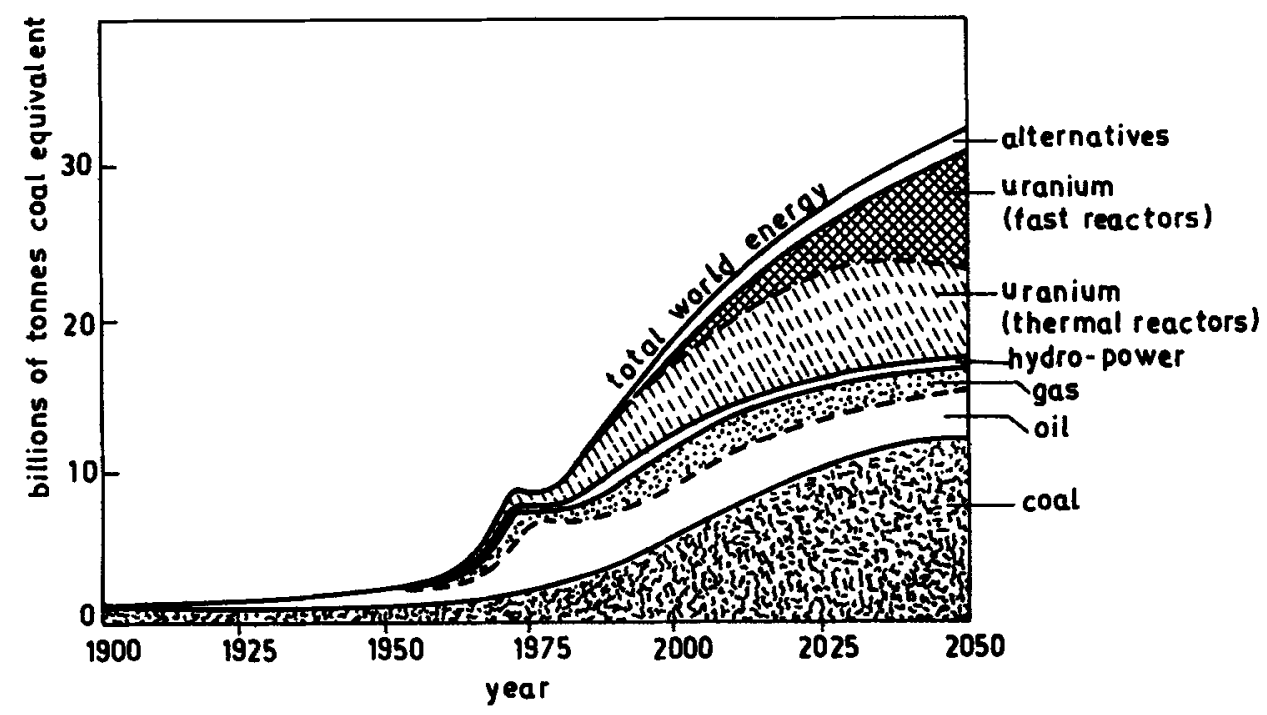

Figure 1. Past and likely future pattern of world energy consumption. 
Table 1. Quantities of different fuels needed to generate one billion kilowatt-hours (or units) of electricity.

\begin{tabular}{lc}
\hline Coal & $124,000 \mathrm{t}$ \\
Oil & $83,000 \mathrm{t}$ \\
Natural gas & $96 \times 10^{6} \mathrm{~m}^{3}$ \\
Hydropower & $37 \times 10^{9} \mathrm{t}$ of water falling $100 \mathrm{~m}$ \\
Uranium - with 1\% utilization in present thermal reactors & $4.9 \mathrm{t}$ \\
Uranium - with $75 \%$ utilization in fast reactors & $65 \mathrm{~kg}$ \\
\hline
\end{tabular}

moderator, as in a fast reactor, it is necessary to use fuel with high fissile contents ranging from $15 \%$ (for a large fast reactor) to over $90 \%$ (for a small fast reactor).

Thermal reactors can be classified into two broad categories depending on the coolant used to extract the heat: water-cooled reactors and gas-cooled reactors. Water-cooled reactors can be further subdivided into light water reactors and heavy water reactors. Light water reactors (LWR) use ordinary water for both coolant and moderator, and need to be fuelled with slightly enriched uranium. There are two types of LWR: the pressurized water reactor (PWR) in which the pressure is high enough to maintain the coolant in the liquid state at all times, and the boiling water reactor (BWR) where the pressure is such that there is controlled boiling in the reactor. Heavy water reactors on the other hand use heavy water as moderator and coolant, with natural uranium as the fuel. The first generation of gas-cooled reactors have used magnox, a magnesium alloy, for cladding natural uranium fuel, and graphite as moderator. Carbon dioxide is used as the coolant. Advanced versions of gas-cooled reactors (AGR) use enriched uranium with stainless steel cladding, and high temperature gas-cooled reactors (HTGR) use ceramic fuels with helium as the coolant. Fast reactors employ liquid sodium as a coolant. In addition to these power producing reactors, nuclear reactors are also important tools for research purposes where the main function is to provide a source of neutrons. Operating temperatures in research reactors are generally low.

\subsection{Nuclear fuels and fuel elements}

At the heart of the reactor is the fuel. Nuclear fuel cannot be charged into a reactor in odd-shaped chunks the way coal is shovelled into a boiler. For efficient utilisation of fissionable content and commenșurate removal of heat generated in the fission process, and for consistency and dependability of performance, it is essential that the fuel is charged in the form of regular-sized 'elements', produced to a high degree of dimensional accuracy and arranged in tidy precision in the coolant channels to conform to reactor geometry. Also, the fuel, which is chemically very reactive, ought not to be directly exposed to the coolant and needs to be clad in a thin leak-proof, corrosion resistant jacket, which also serves to contain the radioactive fission products. The term 'fuel element' has come to be applied to each unit of fuel with its protective jacket, as it is charged into the reactor. The most common geometry for the fuel elements is a cylindrical rod, although plates are sometimes used, e.g. in research reactors. Quite often, these individual fuel elements are assembled together with intervening coolant passages to form a cluster, many such clusters making up the core charge. Such a split-up loading of the fuel (i) helps in the spatial fixation of the fissile material (and the fission products) for easy control of reactivity in the core, 
(ii) provides for satisfactory transmission of heat to the coolant, and (iii) makes it possible to isolate trouble spots as and when they crop up and to discharge damaged or spent units and recharge fresh ones in their place, without necessitating a shut down. While the actual design and anatomy of the fuel element would depend on the particular type and function of the reactor, the power rating and temperature of operation, the nature of the coolant and its rate of flow, it should, however, conform to the following general specifications:

(i) the fuel element should have mechanical and dimensional stability in the operating environment so as to give reasonably long residence time in the reactor core;

(ii) it should represent a delicate balance between maximum surface-to-volume ratio (for good heat transfer) and maximum tolerable ratio of cladding to fuel volume (for neutron economy); and

(iii) it should be relatively inexpensive to fabricate and easy to reprocess.

As the performance of the reactor is strongly dependent on the quality and reliability of the fuel elements, great care has to be taken in the selection of fuel and cladding materials as well as in fuel element fabrication for specific reactor applications.

\section{Types of fuel}

Uranium and plutonium can be used in a number of different forms as nuclear fuels: as metals and alloys or as ceramic compounds such as oxides and carbides. These fuel forms may be introduced into the fuel element in bulk, e.g. cast metal rods or sintered oxide pellets or they may be dispersed in a nonfissionable metal or ceramic matrix. Some properties of important fuels are summarized in table 2 (Simnad \& Howe 1979, pp. 32-179).

\subsection{Metallic fuels}

Metallic uranium is used as a fuel in research reactors. Uranium metal exists in three allotropic modifications, referred to as alpha-, beta- and gamma-uranium, which have different crystal structures. $\alpha$-U stable upto $661^{\circ} \mathrm{C}$ has an orthorhombic crystal structure, $\beta$-U is stable between 661 and $769^{\circ} \mathrm{C}$ and has a tetragonal structure, while $\gamma-\mathrm{U}$ is stable between $769^{\circ} \mathrm{C}$ and the melting point $\left(1130^{\circ} \mathrm{C}\right)$ of uranium and has a body-centred cubic structure. On account of the volume changes that take place during phase transformations, excursions into the beta or gamma region are not tolerated in reactor operation. Cycling through the alpha-beta transition causes "wrinkling" or a surface distortion. This imposes temperature limits on the operation of the reactor.

Cycling $\alpha-U$ at elevated temperatures causes cyclic growth. The orthorhombic crystals elongate in the $a$-direction and shrink in the $c$-direction. The cyclic growth is greater, the higher the temperature to which the metal is raised within the alpha range. In addition to thermal cycling growth, there is the problem of irradiation growth in uranium. During irradiation below about $500^{\circ} \mathrm{C}$, a single crystal of uranium extends in the $\langle 010\rangle$ direction and contracts in the $\langle 100\rangle$ direction. There is no noticeable extension or contraction in the $\langle 001\rangle$ direction. Polycrystalline uranium with the preferred orientation thus changes its shape during irradiation. To maintain 


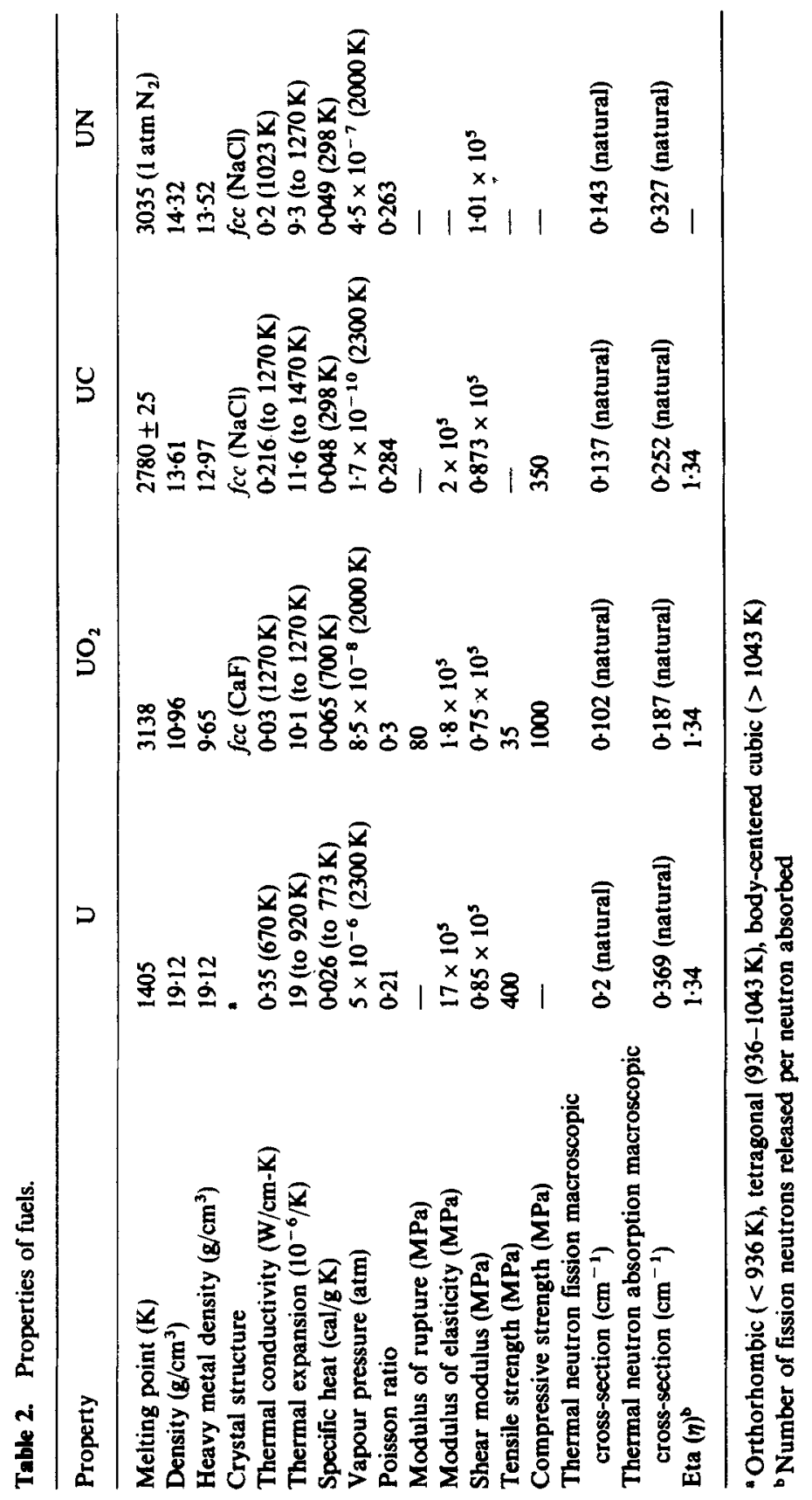


dimensional stability of the metallic fuel element, it is essential, therefore, to produce random texture and small grain size in uranium. This can be achieved by quenching the metal from the beta region. Another solution to these problems would be to stabilize the gamma phase by large alloy additions, such as 10 to $12 \%$ molybdenum, though this will be prejudicial to neutron economy in thermal reactors, unless the uranium is enriched.

Irradiation swelling is another phenomenon which takes place in metallic uranium fuel. There is a net volume increase chiefly due to the gaseous fission products xenon and krypton which, at reactor operating temperatures, tend to precipitate to form gas bubbles. The coarsening of gas bubbles leads to enhanced swelling. The extent to which the bubbles migrate depends on the severity of thermal gradient from the fuel surface to its centre which depends on the rate of fission, but particularly on the thermal conductivity of the fuel. Metallic uranium and uranium alloy have a high thermal conductivity and therefore generate small thermal gradients, typically $\sim 100^{\circ} \mathrm{C} / \mathrm{cm}$. $\mathrm{UO}_{2}$, on the other hand, is a very poor conductor and generates large thermal gradients - typically $2000^{\circ} \mathrm{C} / \mathrm{cm}$. Carbides are an intermediate case, with gradients typically around $500^{\circ} \mathrm{C} / \mathrm{cm}$. Due both to the low temperatures at which metal fuels operate and the small thermal gradients and consequently small driving force for bubble migration, bubbles generally remain quite small. The release of fission gases is negligible. These gases, if released from the fuel, create a pressure on the cladding. Swelling and gas release are the most important effects determining the behaviour of fuel elements.

At higher burn-ups, breakaway swelling has been observed in metallic uranium. This has been attributed in part to grain-boundary cracking and to coalescence of bubbles at the grain boundaries. It has been found that the addition of a few hundred parts per million of iron and aluminium combined with heat treatment (quenching from the beta phase) removed breakaway swelling. This material is known as 'adjusted uranium' and is the standard fuel in the UK magnox reactors.

Compatibility of the fuel with the coolant is also an important consideration. Metallic uranium oxidizes fairly readily in water and $\mathrm{CO}_{2}$. Thus the consequences of cladding failure become serious. $\mathrm{UO}_{2}$ on the other hand oxidizes much more slowly. However, the most favourable property of metallic uranium is its high thermal conductivity which leads to small thermal gradients and low centre-temperature in the fuel. Intermetallic compounds of uranium have been examined and found to have adequate corrosion resistance in water. Uranium-plutonium-zirconium alloys have been developed, with $\mathrm{U}-15 \% \mathrm{Pu}-10 \% \mathrm{Zr}$ as the reference composition for fast reactor applications. This alloy has better compatibility with stainless steel cladding than $\mathrm{U}-\mathrm{Pu}$ fuel. The heavy atom density $\left(14.4 \mathrm{~g} / \mathrm{cm}^{3}\right)$ is also higher than in oxide and carbide fuels and, therefore, should give better breeding performance.

\subsection{Oxide fuels}

Uranium dioxide is the most commonly used fuel today, since it is used in all light water and heavy water moderated reactors. Pellets of sintered $\mathrm{UO}_{2}$ jacketed in thin-walled zirconium alloy tubing have been used in fuel elements. When used as a solid solution with $\mathrm{PuO}_{2}, \mathrm{UO}_{2}$ is the reference fuel for nearly all current fast breeder reactors. The advantages of using $\mathrm{UO}_{2}$ as fuel material as compared to metallic fuel are: (i) no phase change up to the melting point, (ii) good fission product retention, 


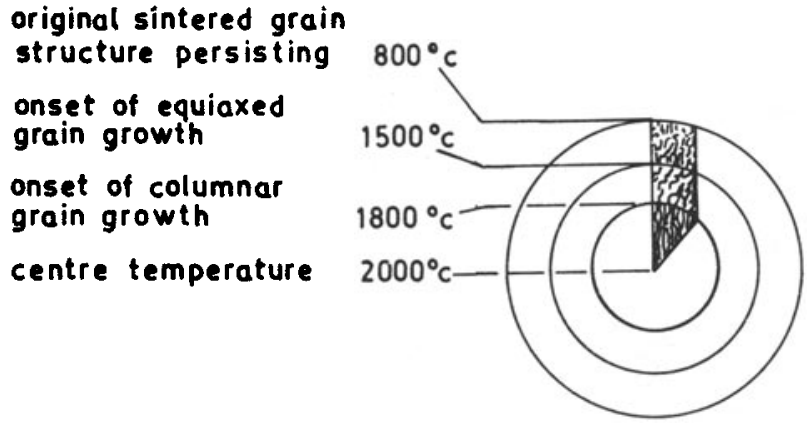

Figure 2. Schematic representation of macrostructure developed in a highly rated $\mathrm{UO}_{2}$ pellet.

(iii) high melting point, (iv) very good corrosion resistance, and (v) good irradiation stability. Disadvantages include relatively low fissionable atom density, low thermal conductivity, low thermal-shock resistance and brittleness. Low thermal conductivity gives rise to large radial thermal gradients in the fuel pellets which lead to restructuring of the fuel (figure 2) (Frost 1969, p. 225). The central portion of the pellet, when it reaches a temperature greater than $1800^{\circ} \mathrm{C}$, develops columnar grains. These are formed by vapour transport within the pores. The temperature gradient existing within the pore evaporates $\mathrm{UO}_{2}$ from the hotter end, which then condenses on the cooler side. Hence the pore moves up the thermal gradient and leaves behind a columnar grain. The various factors that influence the performance of $\mathrm{UO}_{2}$ as a power reactor fuel have been well-understood. These include density, porosity (pore size distribution and pore shape), $\mathrm{O} / \mathrm{U}$ ratio, fission induced densification and restructuring. Since most of the densification takes place due to irradiation-enhanced sintering of small pores ( $\sim 1 \mu \mathrm{m} \mathrm{dia})$, the problem has now been resolved by suitable modification of the powder characteristics and sintering schedules during fuel fabrication so that $\mathrm{UO}_{2}$ pellets do not have pores less than $2 \mu \mathrm{m}$ in size. Volatile fission products like $\mathrm{Rb}, \mathrm{Cs}, \mathrm{I}, \mathrm{Te}, \mathrm{Sb}$ and $\mathrm{Cd}$ are also very important in determining the performance of fuel elements. When pellet cracks connect the clad to the interior of the pellet, some of these volatile products can attack the clad. The situation can be very serious if the clad is already under mechanical stress. This pellet-cladding interaction (PCI) has been identified as the primary cause of cladding failure in water-cooled reactors.

There is evidence to suggest that iodine causes local stress-corrosion cracking of the cladding. In fast reactor oxide fuels, either $\mathrm{Cs}_{2} \mathrm{O}$ or $\mathrm{Cs}_{2} \mathrm{MoO}_{4}$ has been found to react with stainless steel and cause grain boundary attack. This attack can be reduced in two different ways: the starting oxygen/metal ratio of the fuel may be lowered so that excess oxygen is not available to migrate to the cladding or one can use an oxygen getter coating on the inner wall of the cladding.

The main differences between the behaviour and performance of $\mathrm{UO}_{2}$ and mixed oxide fuels arise because the latter is significantly more oxidising. This aspect becomes important in fast reactor fuels which contain large proportions of $\mathrm{PuO}_{2}$. The oxygen potential is the driving force for most of the important in situ reactions in the fuel. The transport of Cs to the cladding and its interaction with it are influenced by the oxygen potential of the fuel. Oxygen potential controls the chemistry of many fission products, their interaction with the fuel and their contribution to fuel swelling. It also influences the reaction between fuel and liquid sodium in LMFBR. The intrinsic thermal 
conductivity of the fuel and the rate and temperature of fuel restructuring are also affected by the oxygen potential.

\subsection{Carbides and nitrides}

Advanced fuels of the type MX (M stands for $\mathrm{U}+\mathrm{Pu}$ and $\mathrm{X}=\mathrm{C}, \mathrm{N}$ or mixed $\mathrm{C}, \mathrm{N}$ composition) offer greater potential for developing breeder systems with doubling time in the range of 8-12 years (figure 3) (Sundaram 1987). Doubling time is a measure of breeding performance and is defined as the operating time for the FBR to produce as much excess fissile material as is normally contained in the reactor (in-pile inventory) and in the associated ex-reactor fuel cycle (out-of-pile inventory). The improved breeding performance is due to higher heavy-metal densities and higher thermal conductivities (table 2, figure 4) (Simnad \& Howe 1979, pp. 32-179; Matzke 1986, pp. 1-35) as compared to oxide fuels, which allow higher linear rating and reduced inventories of fissile materials or more compact core designs to be used.

Some advantages and disadvantages of MX type and oxide fuels for liquid metal cooled fast breeder reactors (LMFBR) are summarized in table 3. Because of their higher thermal conductivities, the centre temperature for carbide and nitride fuels is $1400^{\circ}$ as against $2400^{\circ} \mathrm{C}$ for oxide fuel. The thermal gradients are correspondingly lower. This has a marked effect on fuel behaviour and on fission product distribution. The carbides and nitrides do not restructure and final grain size and shape are similar to

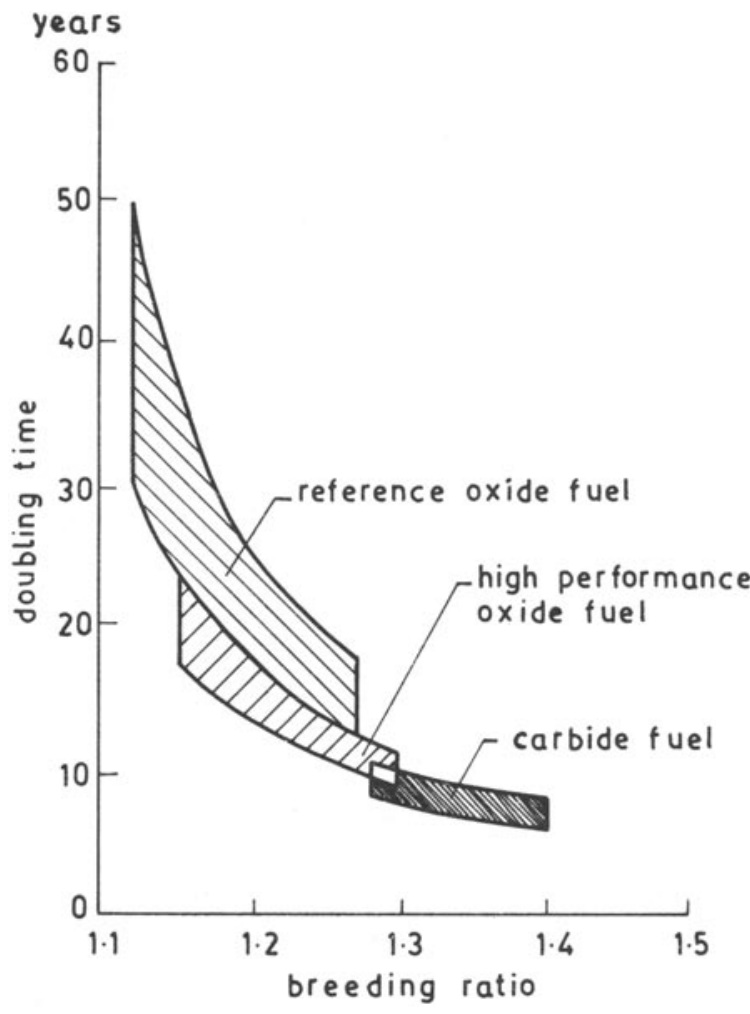

Figure 3. Doubling times for present and advanced LMFBR. 


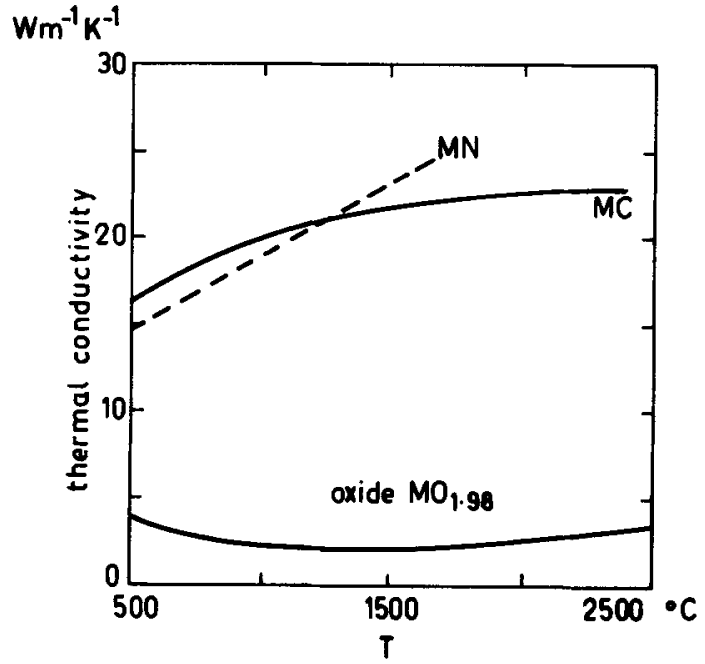

Figure 4. Thermal conductivity of oxide and advanced fuels.

initial grain size and shape. The volatile fission products are less mobile than those of oxide fuels. Also the carbides and nitrides of the fission products do not appear to react with cladding materials in the manner of the oxides. Therefore high gas release and fuel-cladding interactions are absent. On the other hand, the higher densities of carbides and nitrides combined with retention of fission products produce a higher swelling rate. Hence fuel element design must allow for accommodation of this swelling. This is accomplished by a wide $(\sim 10 \mu \mathrm{m})$ sodium bond between fuel

Table 3. Comparison of advanced MX-type fuels and oxide fuels for LMFBR.

Advantages of $M X$ fuels

The higher thermal conductivity allows operating fuel elements at higher linear power. Alternatively, for a given linear power, a pin of larger diameter can be used. This, together with the higher metal atom density, allows the carbide-fuelled reactor to have a lower specific inventory and gives the reactor designer more flexibility.

There is only one non-metal atom per metal atom. The macroscopic capture cross-section is similar, the flux spectrum is harder, thus increasing the number of neutrons per $\mathrm{Pu}$ fission.

These advantages result in an improved breeding gain, promising a shorter doubling time.

Disadvantages of $M X$ fuels

MX-type fuels are less developed than oxides. There is less irradiation experience.

They have a higher swelling rate, hence more care has to be taken in designing fuel elements and operating the reactor.

The steel clad may carburize.

The fuel cycle is less developed. No large-scale industrial experience exists in the fabrication of fuel elements. Reprocessing is more difficult.

With MN fuel, the high capture cross-section of ${ }^{14} \mathrm{~N}(99.6 \%$ abundance in natural nitrogen) is a disadvantage. Disturbing ${ }^{14} \mathrm{C}$ is formed. However, use of enriched ${ }^{15} \mathrm{~N}$ avoids these drawbacks. 
and cladding. Under thermal stresses, these fuel pellets crack into a few large chunks. These chunks may move around and form a "log jam" which can transmit swelling forces to local regions of the cladding and cause failure.

\section{Cladding and duct materials}

The functions of the cladding material are to maintain a barrier between the fuel and the coolant and to maintain the predetermined geometry of the fuel element. In addition to the fuel tube (cladding) containing the fuel, the subassemblies which comprise the reactor core, contain spacers to provide the desired coolant channel size and geometry and ducts to provide strength and to direct coolant flow. Spacers and ducts must not break or distort in service and are, therefore, important non-fuel components of the core. The choice of materials for cladding and duct will vary for different fast and thermal neutron spectra, coolants and fuels.

In general, the cladding has to be a material which (i) can be easily formed to the shape of the fuel and would bond well with it to facilitate heat transfer, (ii) would be compatible both with the fuel on one side, and the coolant on the other, showing no interaction with either, (iii) would remain thermally and mechanically stable under severe operating conditions, (iv) would be resistant to radiation damage, (v) would not build up high activity isotopes of long life and, above all, (vi) which could be transparent to (or have a low absorption cross-section for) neutrons so as to preserve neutron economy.

Table 4 (Frost 1982, pp. 77-97) lists the thermal neutron absorption cross-sections for a number of metals. With a practical upper value of 0.2 barns, one is limited to aluminium, magnesium, zirconium, beryllium and graphite for thermal reactors, although thin stainless steel has been used in British AGR. On the other hand, stainless steels are used extensively in fast reactors, where the cross-sections are lower. A careful control has to be exercised over the amounts of minor elements that have high absorption cross-sections, e.g. boron in stainless steel and hafnium in zirconium.

The cladding is subjected to steadily rising stresses due to fuel-swelling and fission gas release, to a steady coolant pressure on the outside, to thermal stresses that vary with power, and to local, fluctuating stresses at cracks and pellet-pellet interfaces in the fuel column. To withstand these stresses, the cladding must possess and retain good multiaxial rupture strength, creep strength and ductility. The wall of the cladding should be as thin as possible, consistent with adequate mechanical performance, for reasons of good neutron economy and minimum thermal stresses. Due allowance must be made for the corrosion of clad by the fuel and the coolant. Heat transfer and fuel performance considerations would determine the fuel tube diameter.

Aluminium and its alloys are used extensively as the fuel matrix and cladding in research reactor fuel elements. It has been used in our CIRUS and DHRUVA reactors at Trombay. The oxidation resistance and mechanical properties of aluminium are all adequate at the moderate temperatures $\left(\sim 100^{\circ} \mathrm{C}\right)$ where its use is considered.

Magnesium has a lower thermal neutron absorption cross-section than aluminium

Table 4. Values of thermal neutron absorption cross-section of selected elements.

\begin{tabular}{lccccccccccccc}
\hline Element & $\mathrm{Al}$ & $\mathrm{Be}$ & $\mathrm{Cr}$ & $\mathrm{Cu}$ & $\mathrm{Fe}$ & $\mathrm{Mg}$ & $\mathrm{Mo}$ & $\mathrm{Ni}$ & $\mathrm{Nb}$ & $\mathrm{Ta}$ & $\mathrm{Ti}$ & $\mathrm{W}$ & $\mathrm{Zr}$ \\
Barns & 0.23 & 0.010 & 2.9 & 3.7 & 2.5 & 0.063 & 2.5 & 4.6 & 1.1 & 21.0 & 5.6 & 19.0 & 0.18 \\
\hline
\end{tabular}


and can stand higher temperatures. The oxidation resistance of the metal can be remarkably improved with minor additions of aluminium, beryllium or zirconium. Magnesium alloy (magnox) cladding has been adopted for the graphite-moderated $\mathrm{CO}_{2}$ gas-cooled reactors. The low room-temperature ductility and rapid deterioration of creep strength above $400^{\circ} \mathrm{C}$, however, limit the use of magnesium to the narrow temperature range of 250 to $400^{\circ} \mathrm{C}$.

By virtue of its high melting point $\left(1845^{\circ} \mathrm{C}\right)$, excellent corrosion resistance and adequate high temperature strength, zirconium is unique among the low absorption cross-section structural metals. Light water and heavy water moderated and cooled reactors use zirconium alloy cladding; heavy water reactors also use zirconium alloy for the pressure and calandria tubes. Pure zirconium in high pressure water at $\sim 300^{\circ} \mathrm{C}$ gains weight due to surface oxidation, forming a thin protective black film. After a certain time, the rate of weight gain increases (breakaway corrosion) due to film cracking. This phenomenon is associated with certain impurities such as nitrogen, carbon, aluminium, titanium and silicon. To overcome breakaway corrosion, a series of alloys, called zircaloys have been developed. The compositions of these alloys are given in table 5(Cox 1976). Two which are in common use are zircaloy- 2 and zircaloy-4. The addition of iron, chromium, nickel and tin combined with the restriction of the nitrogen content reduces the tendency for film cracking. Zircaloy-4 offers better resistance to hydrogen uptake than zircaloy- 2 .

Austenitic stainless steels (mainly type $\mathbf{3 1 6}$ and its modifications) are used as fuel cladding materials as well as for non-fuel core components in all current generation fast breeder reactors. These materials have excellent high temperature mechanical properties, good compatibility with liquid sodium and adequate resistance to radiation damage. Core materials in FBR are subjected to high doses of energetic neutrons $\left(\sim 2 \times 10^{23} \mathrm{n} / \mathrm{cm}^{2}\right)$ which lead to profound changes in mechanical and physical properties. Two effects are known to occur in non-fissile materials in the intense neutron environment of the nuclear reactor (figure 5) (Sundaram 1988). One is the extensive displacement of atoms from their lattice sites due to elastic interactions with the impinging neutrons. The second is the formation of impurity atoms in the materials by transmutation reactions (e.g., helium by $n, \alpha$ reaction). Both these effects lead to the production of a variety of defect structures depending on the irradiation temperature. The important phenomena arising from these irradiation effects which determine the dimensional and mechanical stability of core components (fuel element cladding and

Table 5. Compositions of the zircaloy series of alloys.

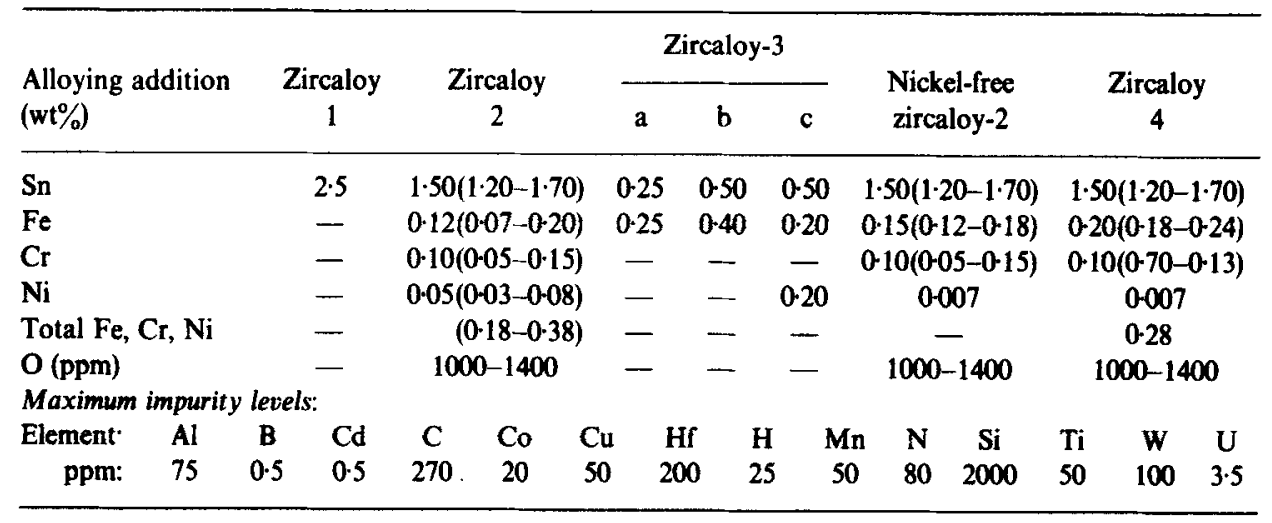




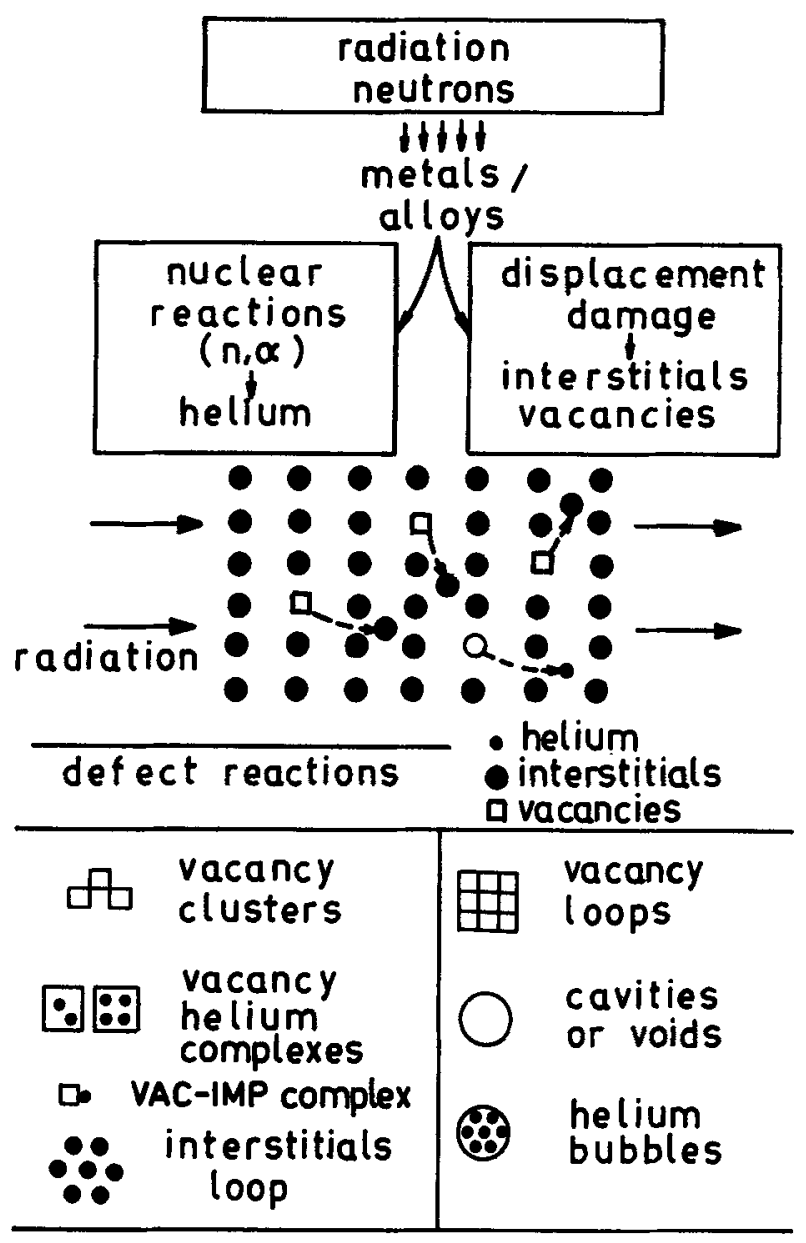

Figure 5. Radiation damage in metals.

subassembly wrappers or ducts) are void swelling, irradiation creep and embrittlement (figure 6) (Sundaram 1988).

Swelling is the volumetric expansion of structural mateials, caused by the formation of voids, that occurs when these are subjected to fast neutron irradiation. Voids nucleate and grow within a narrow temperature range $\left(0.3-0.5 T_{m}\right.$, where $T_{m}$ is the melting point in $\mathbf{K}$ ). This range for stainless steel includes the temperatures at which core materials in LMFBR operate. Void swelling depends sensitively on alloy composition and microstructure. Both major and minor elements have been found to influence swelling resistance of austenitic stainless steels. Minor elements which are particularly effective in increasing the resistance of stainless steels to swelling are $\mathrm{Ti}$ and $\mathrm{Si}$. Ti-modified $316 \mathrm{SS}$ has been selected as reference material for cladding and wrapper for the Prototype Fast Breeder Reactor (PFBR), now being designed at Kalpakkam. Cold working also reduces void swelling. Precipitates play an important role in determining swelling resistance. The reduced swelling of Nimonic PE16 has been attributed to the presence of gamma prime particles. Through modifications in chemical composition and microstructure, it is possible to produce alloys with reduced swelling. 


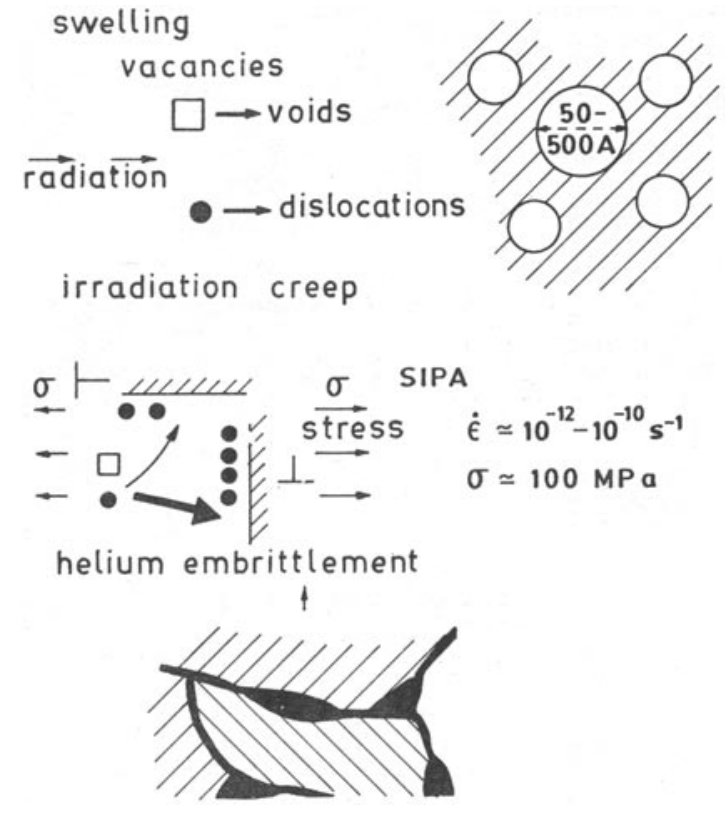

Figure 6. Swelling, irradiationcreep and helium-embrittlement.

Irradiation creep refers either to augmentation of thermal creep by irradiation or to the development of creep under conditions in which thermal creep is absent. This process can lead to excessive deformation and has to be considered in the design of the fuel pin. Another effect of fast reactor irradiation is the phenomenon of helium embrittlement. At high burn-ups required for economic fast breeder reactors, fuel element life may be limited by too small a residual ductility. Helium bubbles that agglomerate at grain boundaries lead to pronounced intergranular fractures and very low ductilities. As it is the formation and growth of helium bubbles at grain boundaries which is responsible for helium embrittlement, the materials in which the growth of helium bubbles at grain boundaries is prevented and transport of bubbles to grain boundaries is retarded would be more resistant to helium embrittlement.

\section{Fuel element fabrication}

Fuel element fabrication is an important step in the nuclear fuel cycle. Fuel cycle comprises uranium mining, through conversion to nuclear grade $\mathrm{U}$ or $\mathrm{UO}_{2}$, fuel fabrication, fuel irradiation, spent fuel storage and finally reprocessing. Fuel fabrication covers all steps from conversion to $\mathrm{UO}_{2}$ powder, pelleting and fuel fabrication. The type of fuel cycle adopted depends on the strategy for nuclear power production adopted by the country. India has developed the complete range of technologies right from mining of the ore to final reprocessing and reuse of spent fuel. Figure 7 (Das \& Prasad 1987) shows the various operations in the nuclear fuel cycle now being carried out within the country. 


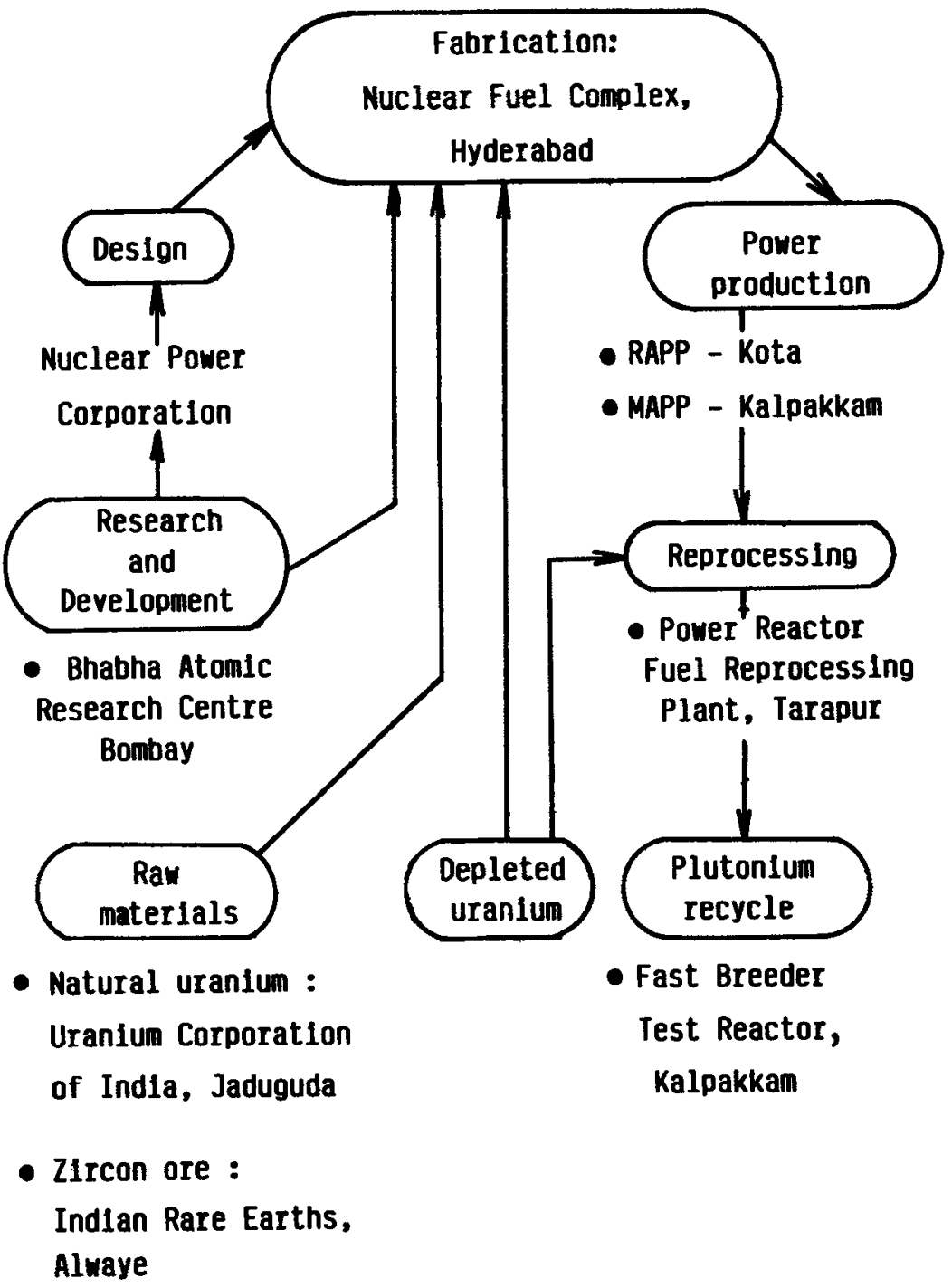

Figure 7. PHWR nuclear fuel cycle in India.

\subsection{Fuel element materials for PHWR}

Natural uranium dioxide is used as the fuel in the form of small sintered pellets stacked inside a clad tube made of zircaloy. Based on the extensive R\&D carried out at the Bhabha Atomic Research Centre (BARC), Trombay, integrated flow sheets for the production of nuclear grade $\mathrm{UO}_{2}$ ceramic fuel (from the Jaduguda concentrate) and zircaloy tubes (starting from mineral zircon) and their assembly into power reactor fuel elements have been established at the Nuclear Fuel Complex (NFC), Hyderabad.

4.1a $\mathrm{U}$ and $\mathrm{UO}_{2}$ : Uranium concentrates received at NFC need to be purified to nuclear standards and this requires the removal of major (water and silicon) and trace impurities (mainly various metals) to ppm levels such that their neutron absorption 


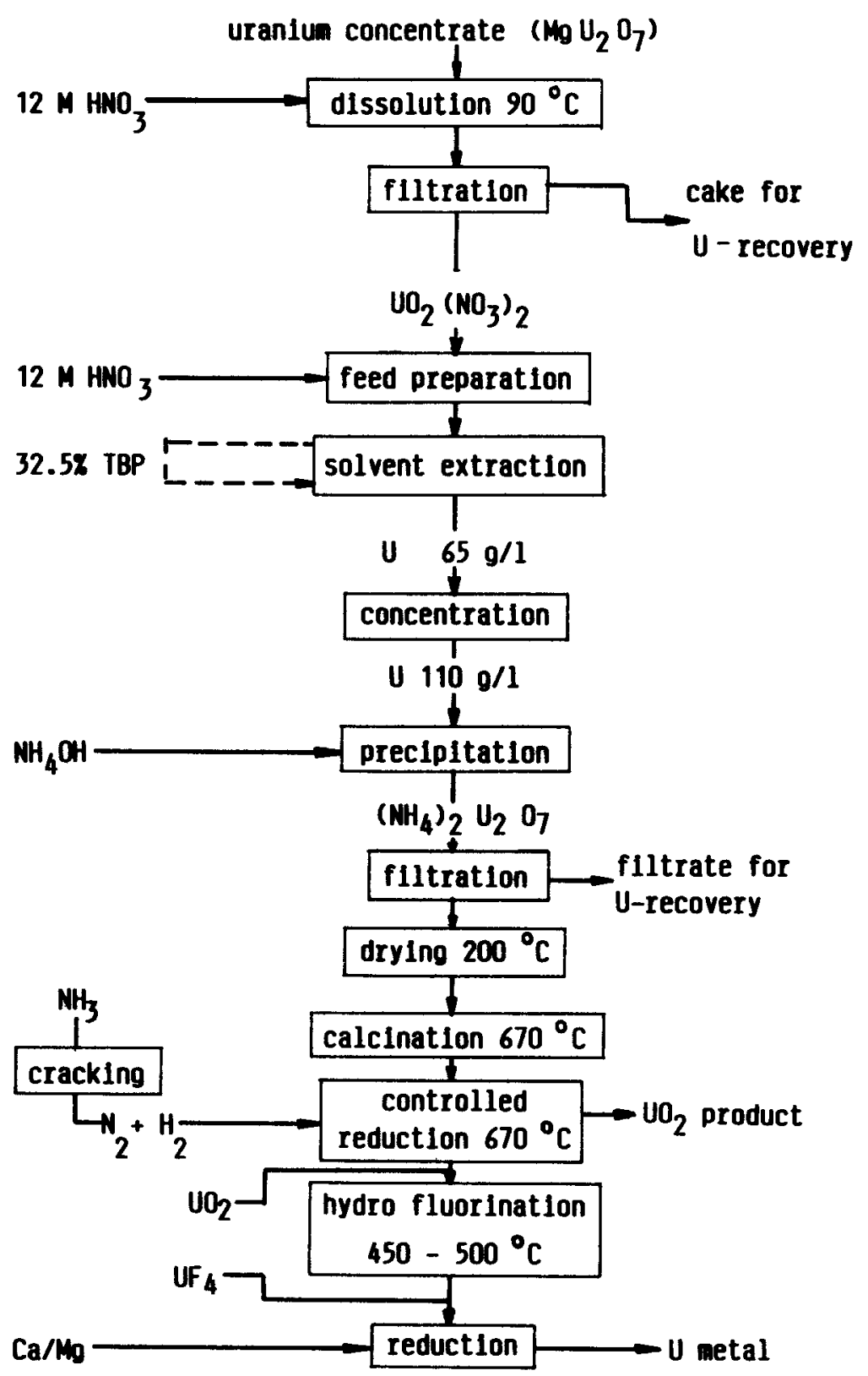

Figure 8. Production of $\mathrm{UO}_{2} / \mathrm{U}$ metal.

cross-section levels are acceptable for in-reactor service. The flowsheet for the production of $\mathrm{U}$ and $\mathrm{UO}_{2}$ powder from uranium concentrate is shown in figure 8 (Sundaram 1988). The uranium ore concentrate is dissolved in nitric acid, filtered and then purified by solvent extraction. Nuclear-pure uranyl nitrate solution is next treated with $\mathrm{NH}_{4} \mathrm{OH}$ to obtain ammonium diuranate (ADU). ADU is dried and calcined in air to get $\mathrm{UO}_{3}-\mathrm{U}_{3} \mathrm{O}_{8}$ which is then reduced to $\mathrm{UO}_{2}$ by hydrogen. The powders produced through the ADU route are amorphous, fine and non-free flowing, having particles of irregular geometry, flaky or needle-shaped, making it necessary to pre-compact and 
granulate them to obtain uniform die-fill during final compaction. On the other hand, the ammonium uranyl carbonate route (AUC) produces granular, crystalline and free flowing particles. After pressing, sintering is carried out to produce $\mathrm{UO}_{2}$ pellets.

The microstructure of the sintered pellets has significant influence on their irradiation performance. Coarse grain $(100-150 \mu \mathrm{m})$ pellets irradiated in the Rajasthan Atomic Power Station (RAPS) have been found to perform well. Another important factor which can influence the performance of the fuel is the degree of porosity and its distribution in the pellet. While higher porosity is preferred from the point of view of gas accommodation, the total porosity has to be limited to a value meeting the requirements of availability of minimum fissile material or minimum pellet density. The size and distribution of this maximum permissible porosity is very important. The porosity should be of the 'closed type'. The size of the closed pores should be such that they do not get annihilated during irradiation.

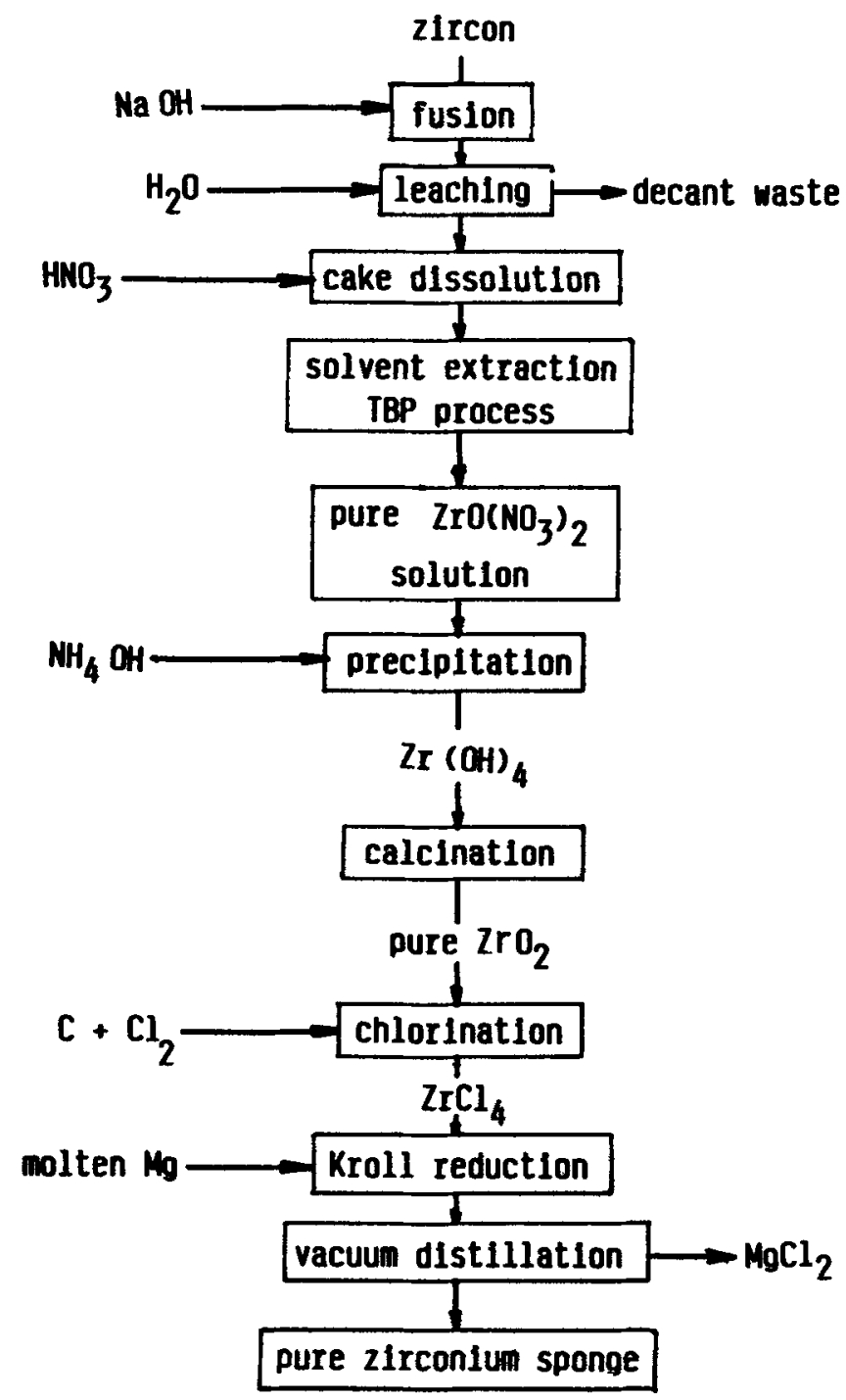

Figure 9. Flow sheet for the extraction of zirconium. 
4.1b Zircaloy cladding: A production plant for nuclear-grade zirconium from mineral zircon has been established at the NFC, Hyderabad (the flowsheet is shown in figure 9) (Sundaram 1988). Hafnium being a poison for neutrons, the need for hafnium-free zirconium for nuclear application has necessitated adoption of the solvent extraction technique for the separation of hafnium. The complete flow sheet for the fabrication of clad tubes for PHWR is shown in figure 10 (Sundaram 1987). This involves vacuum arc melting of ingots, hot extrusion of billets and cold pilgering to the final dimensions. The fabrication route is designed to produce uniform texture for favourable hydride orientation and adequate mechanical properties.

To make the fuel rods, fuel pellets are loaded into zircaloy tubes which are closed at each end by zircaloy end-plugs by a tungsten inert gas (TIG) welding process. Fuel elements are assembled in clusters with wire spacers and other fittings. Very stringent quality control is exercised in the fabrication of fuel boundaries.

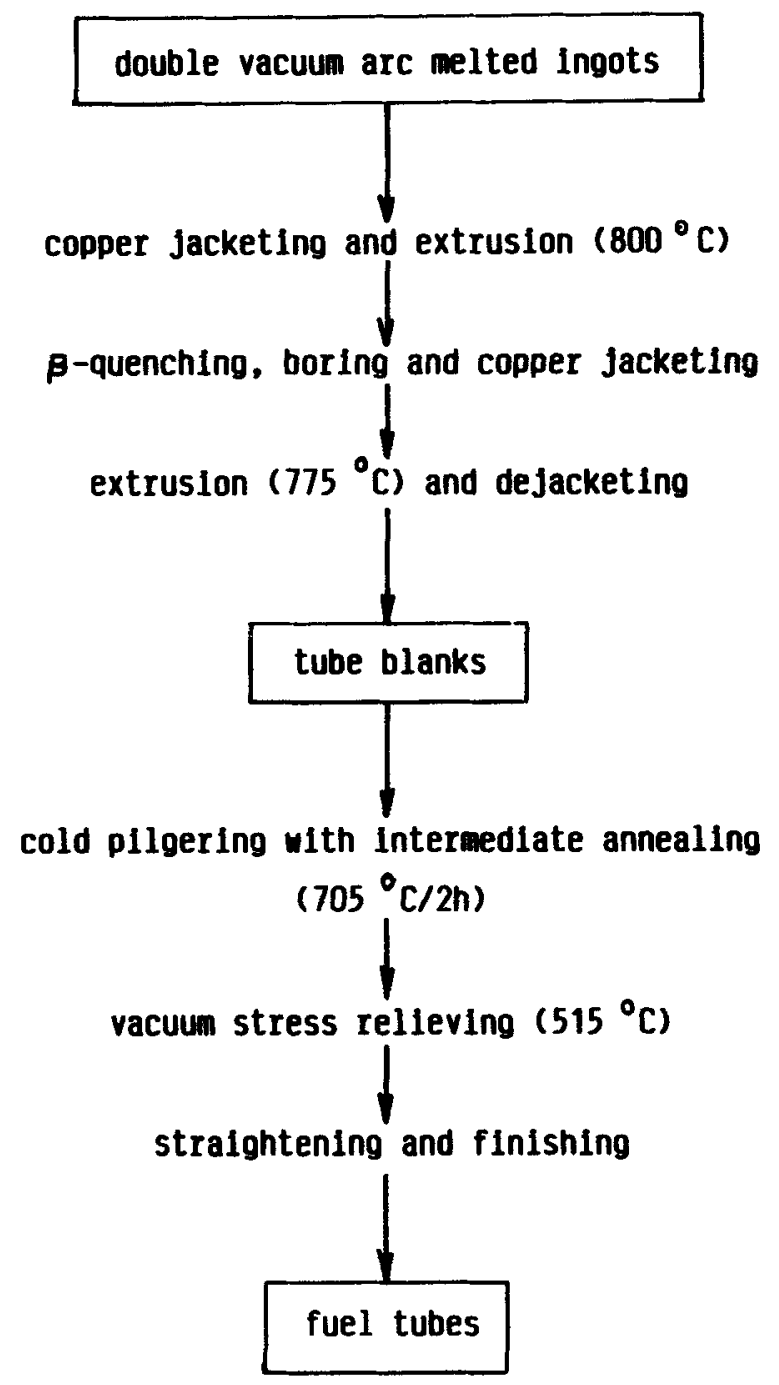

Figure 10. Fabrication of fuel tubes for PHWR. 


\section{Fuel pin design aspects}

Most of the fuel elements and reactor cores are cylindrical. The overall active length of an element derives from neutronic calculations that determine the size and the fuel loading of the reactor. The diameter and the number of pins must satisfy two requirements: that the total volume of the pins contain the required mass of the fuel and fertile material, and that the surface area multiplied by local permissible heat flux and integrated over the reactor core is equal to the required power. $A$ third requirement is a compromise between minimizing fabrication cost and maximizing specific power and forces the diameter into the upper range permitted by the first two requirements. Cladding thickness, strength and neutron absorption enter these three requirements and are vital for fuel burn-up and life.

To get the desired thermal power output, it is necessary to know the neutron flux and spectrum as a function of core position. Heat output per unit volume or power density $(H)$ is

$$
H=N \sigma_{f} \phi E,
$$

where $N=$ fissile atom density per unit volume, $\sigma_{f}=$ fission cross-section, $\phi=$ neutron flux and $E=$ energy per fission event.

Heat transfer calculations then determine the feasible core size and geometry from the standpoint of heat removal, recognizing that the answer will be influenced by the purpose of the reactor. A basic equation for the rate of heat removal from the reactor core is

$$
q=\left(\rho \cdot C_{p}\right) \cdot v \cdot A_{f} \cdot \Delta t_{C},
$$

where $q=$ heat removed per second i.e. the rate of heat removal, $\left(\rho \cdot C_{p}\right)=$ volumetric heat capacity of the coolant, $v=$ coolant velocity, $A_{f}=$ coolant contact area in the core, $\Delta t_{c}=$ temperature change from bottom to the top of the core. Gaseous coolants have low values of $\left(\rho \cdot C_{p}\right)$ even at high pressures so that high gas velocities and high values of $A_{f}$ are needed.

There are several thermal limits on the core design which will influence fuel and cladding dimensions; the coolant must not boil (or at least depart from nucleate boiling), the fuel must not melt at its centre, the fuel-cladding interface temperature must be below that needed for significant reaction or alloying over the fuel element life-time and the cladding must remain cool enough to retain adequate mechanical strength. These thermal limits can be calculated from the knowledge of heat generation and removal rates and the heat flow path from the bulk fuel to the bulk coolant.

The next step is the determination of fuel diameter before the channel diameters and the fuel-element length can be determined. The limits of performance are determined by different phenomena in different fuels. In metallic fuels the fundamental limitation is the reaction kinetics for fuel-cladding reactions. Fuel swelling is another consideration. For oxide fuels, the limitation lies in their low thermal conductivity which varies with temperature. The temperature difference from the surface to the centre of a cylinder of fuel is

$$
\Delta T_{C S}=\sigma_{f} \phi N r^{2} E / 4 k=H \cdot r^{2} / 4 k,
$$

where $r=$ fuel radius, $k=$ fuel thermal conductivity. The variation of $k$ with temperature must be taken into account in the evaluation of $r$. The generally accepted limit on $\mathrm{UO}_{2}$ or $(\mathrm{U}, \mathrm{Pu}) \mathrm{O}_{2}$ performance is centre melting $\left(\sim 2800^{\circ} \mathrm{C}\right)$. The maximum 
value of $r$ can be determined from the known value of $\Delta T_{C S}=T_{\text {melt }}-T_{\text {surface. }}$. All fuel designs using oxide fuels, however, stay away from the fuel-melting temperature, generally operating at $2000^{\circ} \mathrm{C}$ centre temperature, although the PHWR and AGR designs stay below $1500^{\circ} \mathrm{C}$ to keep fission gas release to a minimum because they do not have gas plenum.

The most important performance parameter of a fuel rod is the thermal power per unit length, which is directly related to the integral of thermal conductivity of the fuel material from a permissible temperature at the centre of the cylinder $\left(T_{0}\right)$ to the designed temperature at the edge $\left(T_{a}\right)$. Heat output per unit length, $W_{l}$, is

$$
W_{l}=4 \pi \int_{T_{a}}^{T_{0}} k(T) \mathrm{d} T .
$$

A variation of linear power rating, $W_{l}$, of oxide and carbide fuel elements as a function of the centre temperature of the fuel with the surface temperature at $500^{\circ} \mathrm{C}$ is shown in figure 11 (Simnad \& Howe 1979, pp. 32-179). Carbides are better conductors than oxide and have higher melting points; therefore they can be designed to have much larger diameters. The main point to be made about the thermal conductivity integral in (4), is that the power per unit length of a fuel rod is a material property independent of dimension. Given the thermal power required from the core, the total length of the fuel rod of a given type is specified. Given the length of the core and hence the overall length of the rods, the number of rods is specified.

The choice and thickness of the cladding is arrived at from considerations of minimization of neutron absorption, subject to the requirements of strength and fabrication costs. For oxides in thermal reactors, neutron capture in the cladding sets an upper limit on the thickness. In fast reactors, it is a combination of neutron capture and thermal stress that limits the thickness. The lower limit to the cladding thickness is set by stress calculations with a wastage allowance added, to account for fuel-cladding and coolant-cladding interactions.

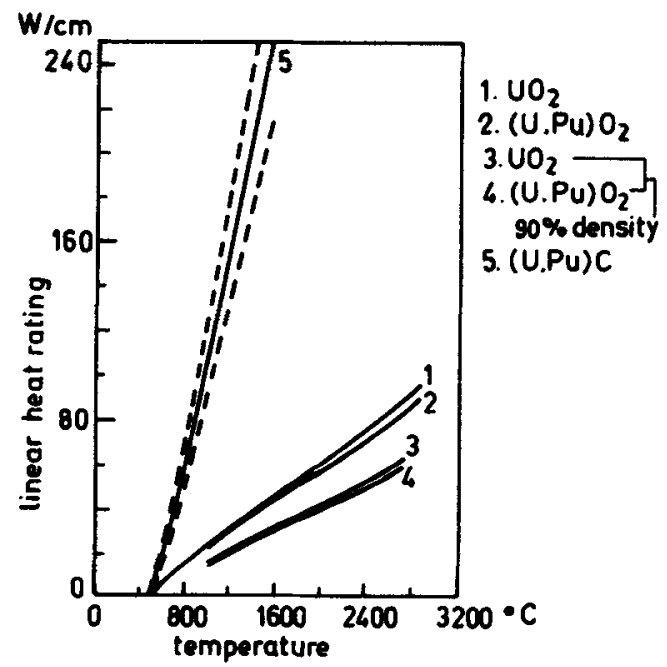

Figure 11. Variation of linear power ratings $W_{1}$ of oxide and carbide fuel elements as a function of the centre temperature of the fuel $T_{0}\left(T_{a}=500^{\circ} \mathrm{C}\right)$.

$$
W_{1} / 4 \pi=\int_{T_{a}}^{T_{0}} k(T) \mathrm{d} T
$$




\section{Fuel elements and their performance in water-cooled reactors}

Fuel elements have performed exceptionally well in the currently operating watercooled reactors. The type of fuel assembly employed depends on the type of the reactor.

\subsection{Research reactors}

The majority of research reactors are cooled and moderated by water. Metallic uranium and alloys of uranium with $\mathrm{Al}, \mathrm{Zr}, \mathrm{Si}$ are used as fuels. Natural uranium is used in heavy water-moderated reactors while light water reactors employ enriched uranium. As operating temperatures in research reactors are low, aluminium is the favoured cladding material. The main limitation on neutron flux is heat transfer because the film boiling of the coolant must be avoided. Hence research reactor fuel elements are generally of plate geometry (figure 12) (Frost 1982, pp. 13-49). The APSARA reactor employs an alloy of aluminium and enriched-uranium plate-type fuel element. CIRUS and DHRUVA, the research reactors at Trombay, use natural metallic uranium as the fuel, the element consisting of a natural uranium rod sheathed in a finned aluminium tube. These rods are fabricated at the Atomic Fuels Division, BARC.

The new reactor at BARC, DHRUVA (a $100 \mathrm{MW}$ research reactor), is fuelled with seven-pin clusters of metallic uranium pins clad in aluminium (figure 13) (Anand 1987, private communication). The important design parameters for the DHRUVA fuel elements are given in table 6.

The cluster subassembly consists of the following components:

(i) lower bulge section,

(ii) hanger plate (bottom tie plate),

(iii) flow tube,

(iv) fuel pins,

(v) spacers,

(vi) guide plate (top tie plate), and

(vii) top bulge section.

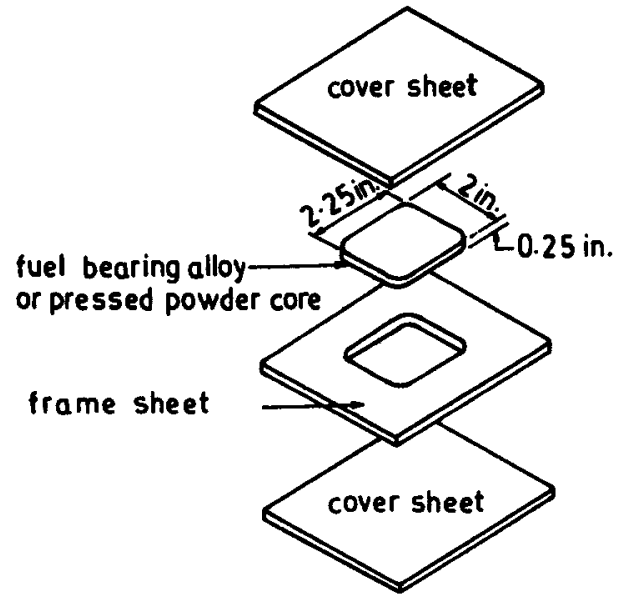

Figure 12. "Picture-frame" assembly of a research reactor fuel element. 


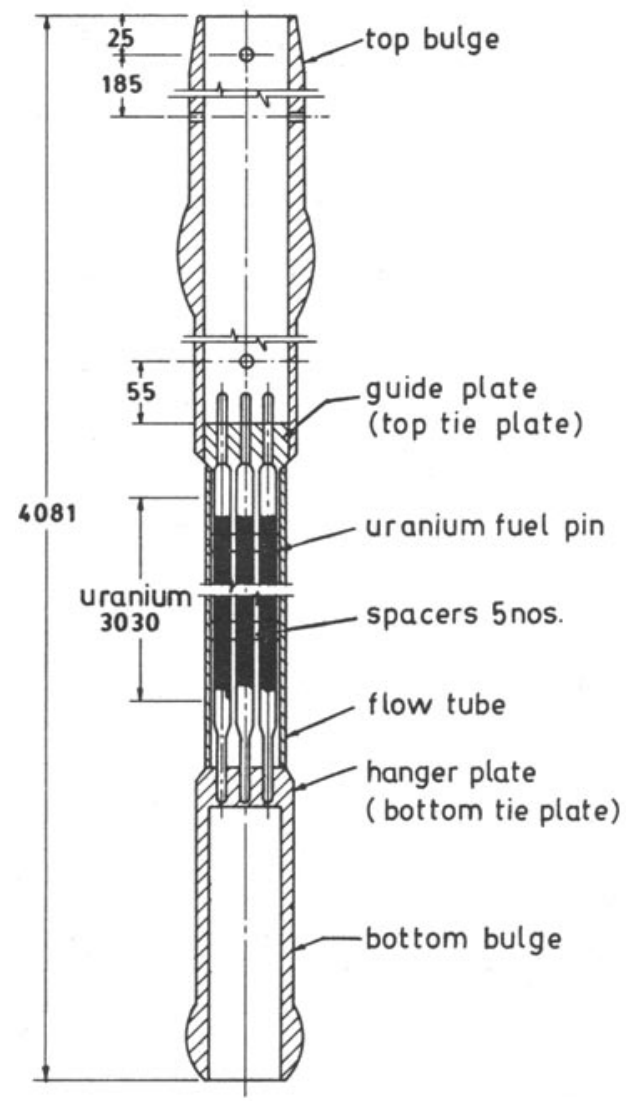

Figure 13. Dhruva fuel cluster.

(i) Lower bulge section - Its purpose is to guide the fuel assembly during installation and to provide support to the fuel assembly in the channel. The bulge has longitudinal slits to make it act as a spring support; the purpose being to.eliminate any clearance at the support location. The material for the lower bulge is aluminium.

(ii) Hanger plate - The hanger plate is welded to the bottom of the flow tube. Its function is to locate and support the fuel pins. The fuel pins' outer end-plugs are welded to the hanger plate. It is made of aluminium.

(iii) Flow tube - The aluminium flow tube houses the seven fuel pins and heavy water coolant. It is welded to the hanger and the guide plates at the bottom and top ends, respectively.

Table 6. Design parameters for DHRUVA fuel element.

\begin{tabular}{ll}
\hline Fuel pin diameter & $12.7 \mathrm{~mm}$ \\
No. of fuel pins & 7 \\
Length of uranium fuel pin & $3030 \mathrm{~mm}$ \\
Clad thickness & $1 \mathrm{~mm}$ \\
Clad material & Aluminium 1S \\
Flow tube material & Aluminium 57S \\
Flow tube I.D. & $57.3 \mathrm{~mm}$ \\
\hline
\end{tabular}


(iv) Fuel pins - Each cluster consists of seven metallic uranium pins. Each uranium pin consists of a $12.7 \mathrm{~mm}$ dia, $3030 \mathrm{~mm}$ long uranium rod clad with $1 \mathrm{~mm}$ thick aluminium finned-tube by cold drawing such that the sheath is in complete contact with uranium without any air pockets.

(v) Spacers - Spacers are used to maintain inter-element spacing. The spacer is essentially a grid plate for fuel location with cut-outs provided for the flow path. Spacers are fixed to the flow tube by means of pins.

(vi) Guide plate - The guide plate is welded to the upper end of the flow tube. It guides the top outer plugs of the fuel pins during expansion or contraction. Its section is similar to that of the hanger plate with the rib section kept to a minimum to maximise the available flow area.

(vii) Top bulge section - This section serves as a flow outlet for the fuel cluster. The purpose of the slit section of the bulge is to provide a stiff support as well as to eliminate any clearance at the support location.

In the design of fuel elements for DHRUVA, the maximum surface temperature of the aluminium cladding is restricted to $126^{\circ} \mathrm{C}$ based on considerations of corrosion rate and residence time for stipulated burn-up in the reactor. This fuel cluster assembly has shown good performance so far.

\subsection{Power reactors}

6.2a Pressurised heavy water reactors: The current Indian nuclear power programme is based on the installation of a series of pressurised heavy water reactors of 235 and $500 \mathrm{MWe}$ capacities. The PHWR fuel cycle involves lower cost and makes more efficient use of the total uranium mined than any other fuel cycle in commercial use today. Typical fuel element design parameters for various types of reactors are given in table 7 (Simnad \& Howe 1979, pp. 32-179). A typical fuel bundle for PHWR is shown in figure 14 (Lawson 1987, pp. 109-111). The choice of the close-packed circular cross-section results from the containment of the fuel and the coolant in small diameter pressure tubes. The PHWR fuel bundle is essentially made up of two materials, ceramic fuel pellets of natural uranium dioxide and zircaloy structural components. The components making up the bundle are $\mathrm{UO}_{2}$ pellets, zircaloy tubes, zircaloy bearingpads and inter-element spacers, zircaloy end-caps for fuel element-closure welds, and zircaloy end-plates which hold the fuel elements in a bundle. The inherent emphasis on neutron economy in natural uranium oxide-fuelled heavy water-moderated and-cooled reactors has resulted in the use of thin-walled collapsible cladding and high density sintered $\mathrm{UO}_{2}$ pellets. The clad being collapsible, close control on axial and diametrical pellet-clad clearances and clad mechanical properties is very necessary to avoid excessive sheath strain resulting in collapse. An average burn-up of over $7000 \mathrm{MWd} / \mathrm{t}(\mathrm{U})$ can be achieved and the nominal maximum thermal power output in individual elements is limited to $50 \mathrm{~kW} / \mathrm{m}$.

6.2b Pressurised water reactors: In PWR, the fuel rods are assembled with a square array held together by spring clips or spacer grids and by nozzles at the top and bottom (figure 15) (D' Amore 1987, pp. 104-108). The PWR fuel pin is of full core length. It comprises a zircaloy fuel tube to contain the stack of enriched $\mathrm{UO}_{2}$ pellets and a hold-down spring which serves to maintain the pellets in a continuous length. The spring is contained within the plenum area at the top of the fuel pin which also 
Table 7. Typical fuel element design parameters.

\begin{tabular}{|c|c|c|c|c|}
\hline Characteristic & PWR & BWR & PHWR & LMFBR \\
\hline Fuel material & $\mathrm{UO}_{2}$ pellets & $\mathrm{UQ}_{2}$ pellets & $\mathrm{UO}_{2}$ pellets & $\mathrm{UO}_{2}-\mathrm{PuO}_{2}$ pellets \\
\hline Fuel density $\left(\mathrm{g} / \mathrm{cm}^{3}\right)$ & $10 \cdot 3(94 \%)$ & $10.3(94 \%)$ & $10.6(96.7 \%)$ & $9.90(91 \%)$ \\
\hline Pellet diameter (mm) & 9.29 & 12.4 & $14 \cdot 25$ & 4.94 \\
\hline Fuel portion length (mm) & 3650 & 495 & 500 & 900 \\
\hline Fuel initial enrichment $(\%)$ & 3.0 & 2.5 & 0.7 (natural) & $15(\mathrm{Pu})$ \\
\hline Fuel peak temperature (K) & 2530 & 2690 & 2270 & 2470 \\
\hline Fuel average burn-up (MWd/kg) & $24 \cdot 4$ & $27 \cdot 5$ & 9.0 & 100 \\
\hline Fuel maximum burn-up (MWd/kg) & 35 & 40 & - & 150 \\
\hline Fission gas release $(\%)$ & $1-4$ & $1-4$ & $1-4$ & $80-100$ \\
\hline Fuel-clad gap (diametral) (mm) & $0 \cdot 18$ & 0.25 & 0.08 & 0.18 \\
\hline Cladding material & $\mathrm{Zr}-4$ & $\mathrm{Zr}-2$ & $\mathrm{Zr}-2$ & $20 \% \mathrm{CW} 316 \mathrm{SS}$ \\
\hline Cladding wall thickness (mm) & 0.62 & 0.81 & 0.38 & 0.375 \\
\hline Cladding peak temperature $(\mathbf{K})$ & 620 & 569 & 583 & 920 \\
\hline \multicolumn{5}{|l|}{ Cladding fast neutron fluence } \\
\hline$(0.1 \mathrm{MeV})$ & $10^{22}$ & $10^{22}$ & $10^{22}$ & $3 \times 10^{23}$ \\
\hline \multicolumn{5}{|l|}{ Fast neutron flux $(0.1 \mathrm{MeV})$} \\
\hline (average) & $2 \times 10^{14}$ & $2 \times 10^{14}$ & $4.5 \times 10^{13}$ & $5 \times 10^{15}$ \\
\hline No. of pins per element & 204 & 49 & 28 & 271 \\
\hline No. of elements per channel & 1 & 1 & 12 & 1 \\
\hline Average core rating $(\mathrm{W} / \mathrm{g})$ & $34 \cdot 8$ & $22 \cdot 0$ & $22 \cdot 1$ & 170 \\
\hline Peak heat rating $\left(W / \mathrm{cm}^{2}\right)$ & $171 \cdot 2$ & 134 & $126 \cdot 1$ & 230 \\
\hline Linear heat rating (peak) $(\mathrm{W} / \mathrm{cm})$ & 577 & 600 & 603 & 475 \\
\hline Average power density ( $\mathrm{kW}(\mathrm{th}) /$ litre) & 90 & 50 & 10 & 300 \\
\hline
\end{tabular}

accommodates the gaseous fission products. The pin is closed at each end by welding a zircaloy end plug to the fuel tube and it is filled with helium. Pin design is based on a strong clad concept in which the cladding withstands the reactor coolant pressure so that the gap between fuel pellets and clad closes only gradually as a result of fuel dimensional changes due to irradiation and creep down of the clad under the differential pressure between reactor coolant and pin internal gases.

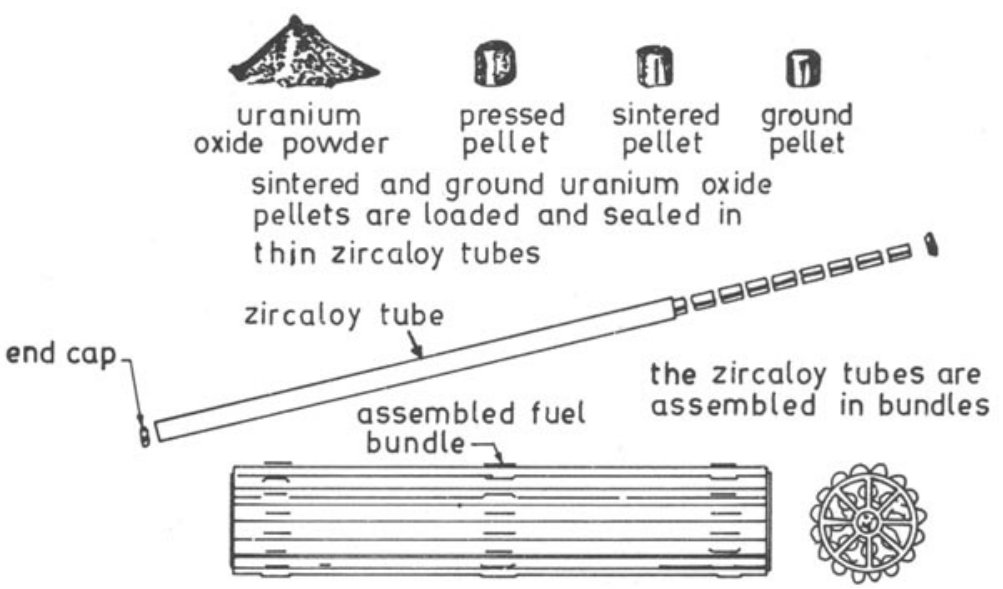

Figure 14. Fuel bundle for PHWR. 


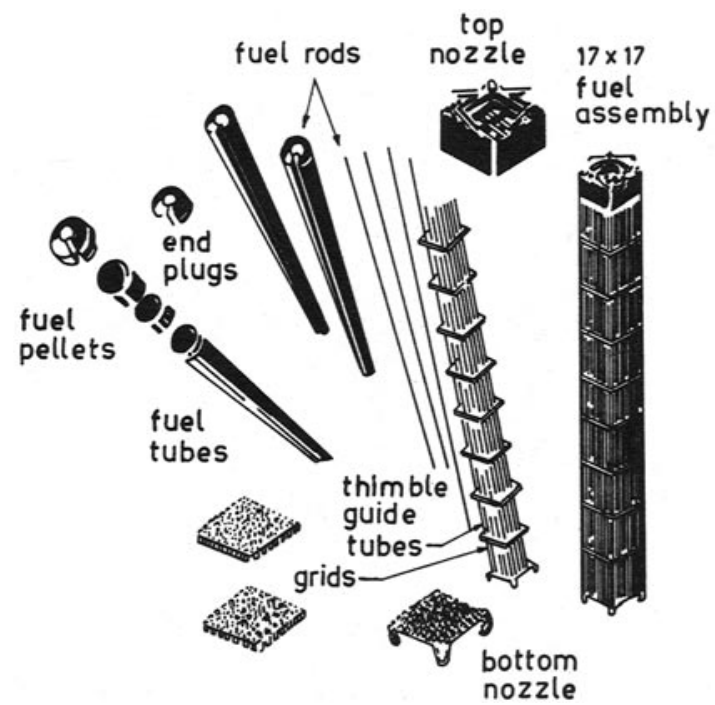

Figure 15. Arrangement of fuel rods in fuel subassemblies in PWR.

6.2c Boiling water reactors: BWR fuel subassemblies are very similar to those of the PWR, with clusters of long elements containing enriched uranium dioxide sealed in zircaloy cladding tubes. The spacing of the elements within the assembly is slightly larger, allowing for the reduced moderator efficiency of the boiling water surrounding them. The fuel assemblies contain only fuel rods (PWR contains control rods also) arranged in $6 \times 6,7 \times 7$ or $8 \times 8$ arrays. The assembly is contained within a zircaloy channel which confines the coolant flow.

\subsection{Factors affecting fuel performance and remedial measures}

Over the years, the fuel element reliability for water-cooled reactors has increased significantly. The mechanisms responsible for fuel element failure have been identified and remedial measures incorporated in fabrication and operational schedules.

6.3a Hydriding of zirconium alloys: Excessive hydriding of zircaloy cladding could lead to performance-limiting embrittlement. External hydriding occurs as a result of hydrogen absorption by the metal during corrosion in water and steam. The solubility of hydrogen in $\alpha$ zirconium is very low at room temperature and is about $150 \mathrm{ppm}$ at a temperature of $350^{\circ} \mathrm{C}$. The extent to which the hydrides embrittle the clad depends on the orientation of the hydrides in the tubes. Formation of radial hydrides is an undesirable situation as it greatly reduces ductility, while circumferentially oriented hydrides have only a marginal effect. Crystallographic texture has an important influence on the orientation of the hydrides. For a favourable hydride orientation, it is necessary that the grains are oriented with the basal plane normals close to the radial direction. This texture is achieved by using large ratios of wall thickness feduction to tube diameter reduction during processing.

Cladding can be attacked at the inside surface of the tube due to hydriding. The defects due to internal hydriding are characterized by bulges and blisters on the clad surface and are known as 'sun bursts'. These sun bursts, with their associated cracks, 
can lead to local penetration of the cladding. Hydride failures can be largely eliminated by the use of very dry atmospheres during post-sintering operations or by a vacuum degassing process so as to bring the residual moisture in the fuel down to a level of $1 \mathrm{ppm}$ or less. Care must also be taken to exclude all other hydrogenous materials from the fuel rod components during manufacture.

6.3b Dimensional stability: The life of extended burn-up fuel assemblies has been limited by the mechanism of differential irradiation growth of zircaloy fuel-assembly components. Different rates of growth arise because of variations in the environment (fluence and temperature) and variations in the metallurgical structure of zircaloy (crystallographic orientation and degree of cold work). Once the variation in growth rate is well known, the range may generally be accommodated by design modification. The range may itself be reduced by limiting the residence of the fuel assemblies in high flux gradient locations.

6.3c Fretting and wear: Flow induced vibrations can cause fretting and wear between the cladding and the grids. The open structure of the PWR assembly makes this system more susceptible. In BWR, vibration has caused fretting of flow channels. Clad failures due to fretting have been rare. When failures do occur, they have been traced to inadequate quality control during spacer fabrication-specifically the manual adjustment of spacer dimensions or manual loading of fuel rods. These types of failures are being minimized or eliminated by increasingly automated fabrication, inspection and assembly procedures.

6.3d Pellet densification: Under irradiation, the fine pores $(\sim 1 \mu \mathrm{m}$ diameter $)$ disappear leading to densification of the pellets. This can lead to clad collapse and is particularly important in a long fuel column such as in PWR. Two remedies have been found for this effect. First, all PWR rods have been prepressurised with helium to prevent cladding collapse. Second, fuel fabrication processes can be designed to eliminate small pores from the miorostructure.

6.3e Pellet-cladding interaction: Pellet-cladding interaction (PCI) is the most persistent and troublesome cause of cladding failure. These failures arise due to the rapid rate of power ascension and are more prevalent in high burn-up rods. Factors which influence $\mathrm{PCI}$ include ramp rate, post-transient power, the transient power increase, burn-up and dwell-time at post-transient power. The cause of PCI failures has been identified as stress corrosion cracking (SCC) of zircaloy. In water reactors, the cladding is subject to high external pressure from the coolant which forces it down onto the pellet at all times. Thus local high stresses are introduced in the cladding at pellet-pellet interfaces and where thermal shock cracks reach the pellet surface. During a power ramp, the fuel expands faster than the cladding, increasing the local stresses. At the post-transient power level, volatile fission products, including iodine and cesium are released into the fuel-clad gap and cause scC of the zircaloy in the region of high local stresses.

Failures due to $\mathrm{PCI}$ were mitigated by implementation of recommendations on operating conditions that limited the rate of power increase. This, however, impacts on the capacity factor of the plant and alternative remedies have been considered that could alleviate or remove the operating restrictions. First, the change to smaller rod diameters has led to reduced fuel temperature and a lower tendency to release 


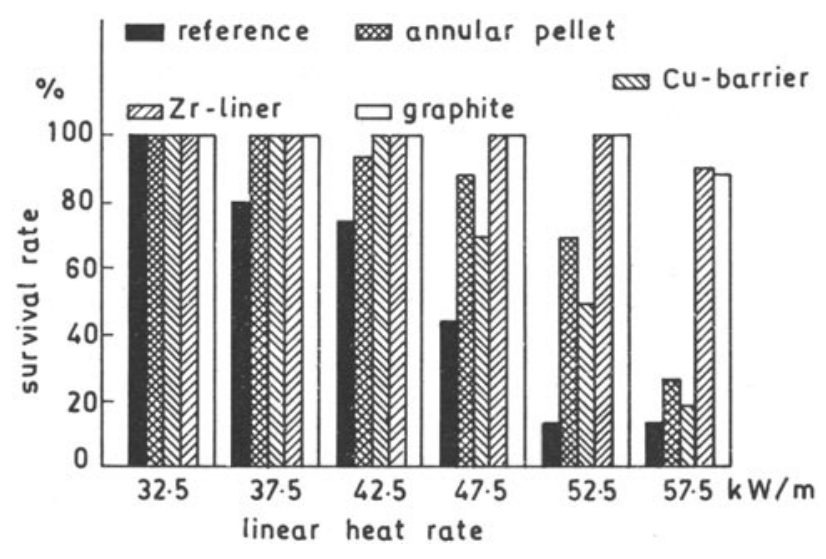

Figure 16. Comparison of the survival rate of various fuel designs during ramp tests over a burnup range between 15 and $39 \mathrm{MWd} / \mathrm{kg} \mathrm{U}$.

fission products. Prepressurisation has helped to reduce cladding stresses. Great success has been obtained in eliminating PCI failures by the use of coatings or liners between the fuel and the cladding (figure 16) (Strasser 1986). Graphite coating (a few microns thick) on the inner surface of the cladding is now a standard design feature of PHWR fuel. Graphite coating is considered to reduce fuel-cladding mechanical interaction and also acts as a diffusion barrier to fission products. Other materials for use as barriers are copper and zirconium. Comparison of copper and zirconium barrier fuels has shown that the copper barrier fuel has a significantly lower margin to failure than the zirconium one. Other reasons for favouring zirconium over copper are the reluctance to put a new material in the core and reprocessors' distaste for copper.

Pellet-clad mechanical interaction can be reduced by certain modifications of pellet shape like chamfering, low $L / D$ ratio and making them annular.

6.3f Corrosion: Clad corrosion, particularly what General Electric described as crud-induced localized corrosion (CILC), has been the cause of a large number of BWR fuel failures. The cause of failure, as currently understood is a combination of three factors: zircaloy prone to nodular corrosion, high copper content reactor water, and a power history conducive to deposition of copper on clad surfaces with nodular corrosion. The dense crud deposits result in overheating and oxidation of clad. The remedy for this failure mechanism is improved corrosion-resistant cladding, achieved by heat treatment and significantly improved water chemistry control. A maximum copper content of 0.1 parts per billion is recommended for the feed water and of ten parts per billion for the reactor water.

\section{Gas-cooled reactors}

\subsection{Carbon dioxide-cooled reactors}

7.1a Magnox reactors: The first generation nuclear power reactors in Britain and France were cooled by carbon dioxide gas. These reactors were graphite-moderated and fuelled with natural uranium metal (adjusted) rods clad in a magnesium alloy. The rods are heat-treated to produce a fine grain size which has a slight texture. Anti-ratchetting grooves are machined in the bars which are then clad in finned 


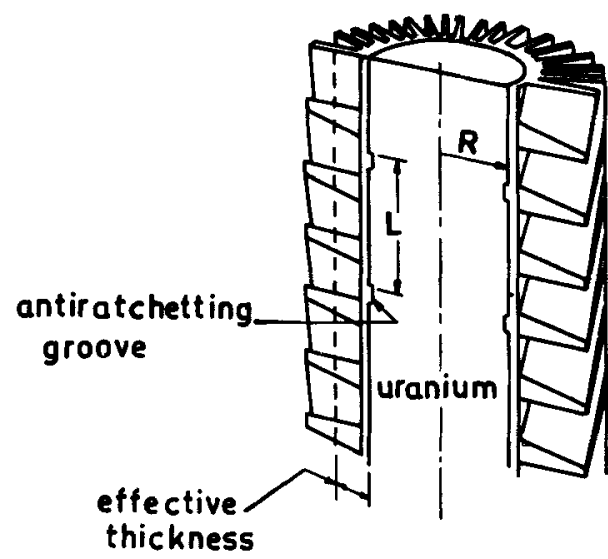

Figure 17. Details of magnox fuel element assembly.

magnox cans (figure 17) (Simnad 1971). The fins are necessary to produce the turbulence and extended surface area for adequate cooling of the fuel in the $\mathrm{CO}_{2}$ coolant. The fuel temperature is kept below $665^{\circ} \mathrm{C}$ to avoid transformation in the uranium. In general, the performance of these fuel elements has been satisfactory. The main cause of failure has been a brittle form of cracking between large grains in the can wall. The problem has been solved by controlling the manufacturing process to avoid texture and grain growth.

7.1b Advanced gas-cooled reactor: The second generation $\mathrm{CO}_{2}$-cooled graphitemoderated reactors in Britain (the advanced gas-cooled reactor, AGR) use slightly enriched $\mathrm{UO}_{2}$ clad in stainless steel (Fe-20Cr-25Ni-0.5Nb). These fuel elements can operate at higher temperatures, to much greater burn-ups, giving higher efficiencies and ratings. There are typically eight fuel elements making up the full core length. The pins are shorter than those in the PWR. The gas plenum space to accommodate the fission gas is provided by the dished ends and the central hole in the annular fuel pellets. An additional benefit of the annular pellets is that they reduce the fuel central temperature and hence the fission gas release. They also provide expansion room in the centre of the fuel to accommodate ramp-induced swelling and minimise failure.

The use of stainless steel for the clad incurs a potential penalty because of its relatively high neutron absorption characteristics. To keep this as low as possible, a thin and hence weak cladding is adopted for the pin design. The weak clad concept needs a stable fuel - that is, fuel of high density and good resistance to in-reactor densification.

\subsection{Helium-cooled reactors}

The high temperature gas-cooled reactors (HTGR) use helium gas at about $800^{\circ} \mathrm{C}$ and $5 \mathrm{MPa}$ as the primary coolant, graphite as the neutron moderator and fuel element structural material and coated (Th-U) carbide or oxide fuel particles dispersed in a graphite matrix as the fuel. The fuel is in the form of microspheres of about $1 \mathrm{~mm}$ overall diameter (figure 18) (Nibielek \& Heit 1987, pp. 118-121). In each microsphere, a kernel of $\mathrm{UO}_{2}$ is surrounded by successive layers of pyrocarbon and silicon carbide. The function of the porous layer surrounding the fuel kernel is to absorb damage from recoiling fission fragments and to provide free volume for the fission gases. The 


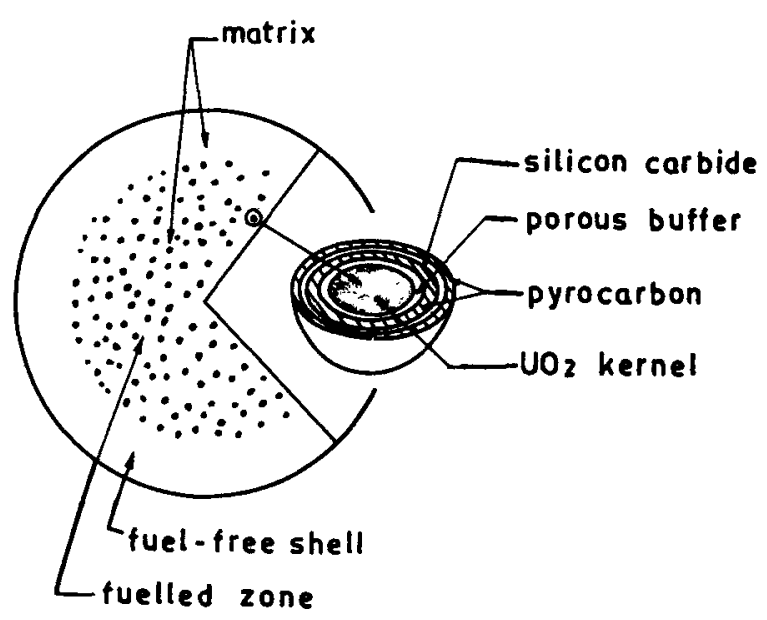

Figure 18. Relationship of coated particle to pebble fuel element.

high density pyrocarbon layer serves the purpose of being the first component in the pressure vessel shell and also acts as a barrier to fission product migration. The $\mathrm{SiC}$ layer is an excellent barrier against release of high temperature fission products. The outer pyrocarbon layer serves as a further barrier to fission products and is also a protective layer for $\mathrm{SiC}$. This type of dispersed fuel transmits its energy efficiently so that the fuel maximum temperature is only a little above the coolant exit temperature. A variety of fuel elements have been considered including honeycombed prismatic blocks through which helium circulates or spheres over which it flows. In the latter, the German concept, the macrosphere elements are each about the size of a tennis ball and are made into a pebble bed through which the helium flows. New pebbles can be added continually while spent pebbles can be discharged from the bottom, allowing on-line refuelling.

The coated particle can be regarded as a miniature fuel can where the ceramic coating layers act as both a composite pressure vessel and a primary barrier to fission product migration. The coated particle fission-product containment system has a number of specific safety advantages by which (a) the fission products are contained at their source, rather than after some degree of dispersal, and (b) the fission product containment system is distributed over about $10^{10}$ microspheres, rather than depending on a few barriers.

\section{Fast breeder reactors}

Fast breeder reactors (FBR) constitute the second phase of the Indian nuclear power programme. Dr. Bhabha envisaged a three-stage atomic power programme for India as indicated in figure 19 (Sundaram 1987). Under the first stage of the programme, a series of PHWR is being set up. The nuclẹar reactor base using PHWR is expected to reach $10 \mathrm{GWe}$ by the year 2000 and the readily available natural uranium in the country will be entirely committed to these reactors over their life time. Besides producing power, the PHWR will convert a part of U-238 in natural uranium into fissile plutonium ( $\mathrm{Pu}-239)$. This plutonium can be separated from the spent fuel in chemical reprocessing plants; facilities for fuel reprocessing are available in the country. The second stage of the nuclear power programme envisages the utilization of 


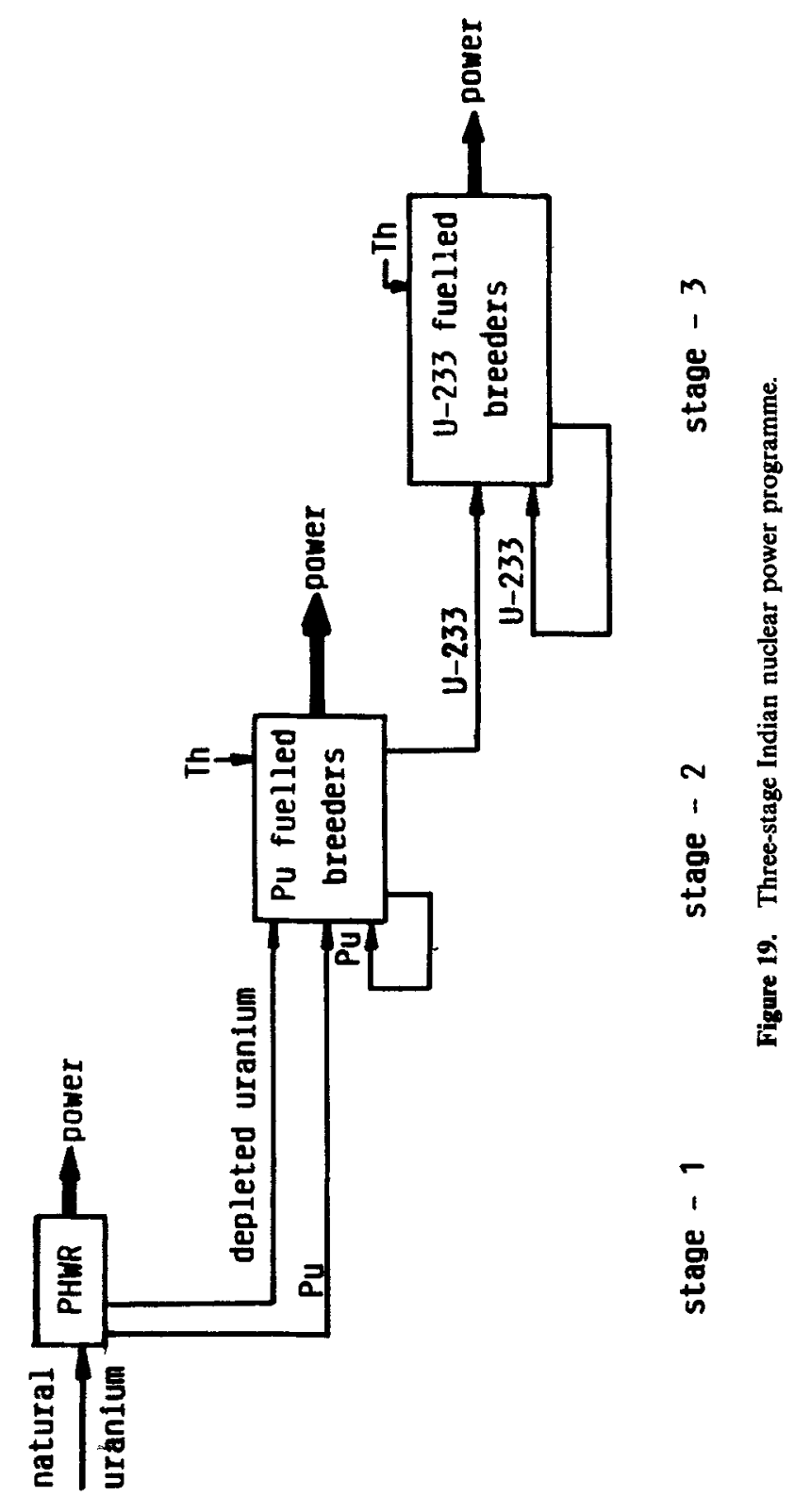


Table 8. Typical features of the LMFBR.

No moderator, therefore fast neutrons $(E>0.1 \mathrm{MeV})$ for energy generation and breeding.

High neutron energy leads to small cross-sections and enables a high power density to be obtained. Therefore

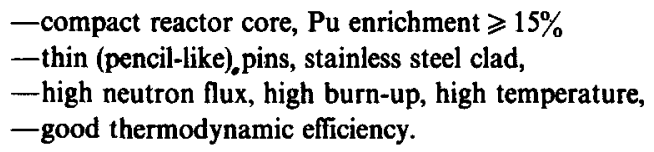

Sodium as coolant because of high power density. Therefore

-low pressure primary system,
-emergency cooling not complicated (natural convection),
-inert gas and secondary $\mathrm{Na}$ systems necessary.

plutonium and U-238 to rapidly increase the nuclear base to several hundred GWe by means of liquid metal-cooled fast breeder reactors (LMFBR). The third stage will be to sustain and consolidate the nuclear electric base by means of thorium breeders. A beginning for the second stage in our strategy for nuclear power development was made on October 18, 1985, when the fast breeder test reactor (FBTR) at the Indira Gandhi Centre for Atomic Research (IGCAR) attained first criticality. Simultaneously, efforts have been initiated towards the design of a $500 \mathrm{MWe}$ prototype fast breeder reactor (PFBR). Typical features of an LMFBR are summarized in table 8.

FBR are attractive in terms of conservation of energy resources because they are able to utilize nuclear fuels about sixty times more effectively than the present generation thermal reactors. The total fuel cycle (figure 20) (Swanson 1987, pp. 122-125) is, however, very important for this utilization of resources. The manufacture of the fast reactor fuel and the reprocessing and recycling of plutonium and uranium in the form of replacement fuel are relatively expensive processes but the costs are offset by the exceptional performance characteristics of this reactor. A high burn-up is desired to bring down the fuel cycle cost (figure 21) (Swanson 1987, pp. 122-125). Current efforts aim at doubling of commercial burn-up targets from around 10 to $20 \%$.

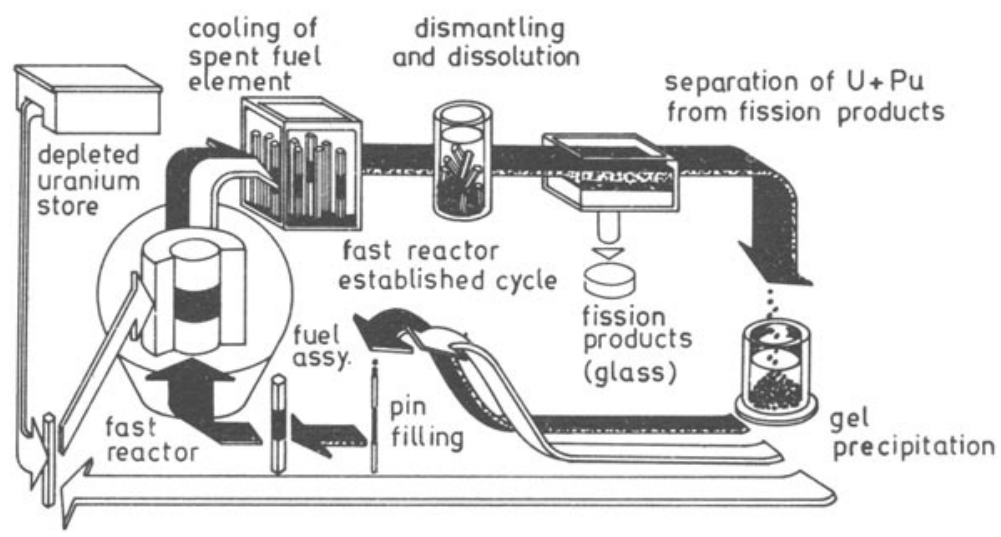

Figure 20. FBR fuel cycle. 


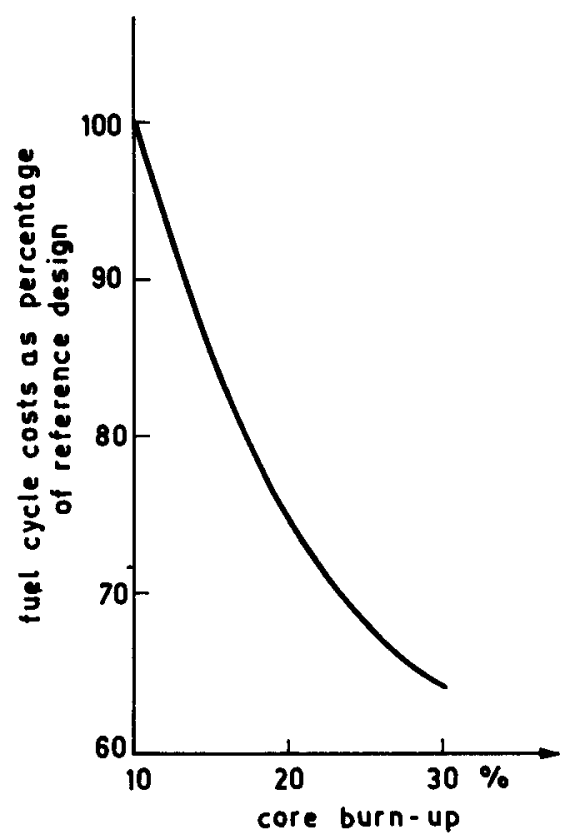

Figure 21. Variation of fuel cycle costs with increasing fuel burn-up.

\subsection{FBR fuel elements}

Fast reactor fuel elements are smaller than thermal reactor elements (figure 22) (Simnad \& Howe 1979, p. 132). The fuel pellets (most reactors use uranium/plutonium oxide) are cylindrical in shape and are stacked in stainless steel cladding tubes with extrenal diameters usually in the range 5.8 to $8.5 \mathrm{~mm}$. The plutonium content of the fuel in the power-producing core of the reactor is generally in the range of 18 to $30 \%$. Above and below the stack of fissile pellets there are pellets of uranium, forming the axial blankets and space (plenum) for the collection of fission product gases. Bundles of these fuel pins, usually 200 to 300 , are incorporated in subassemblies, several

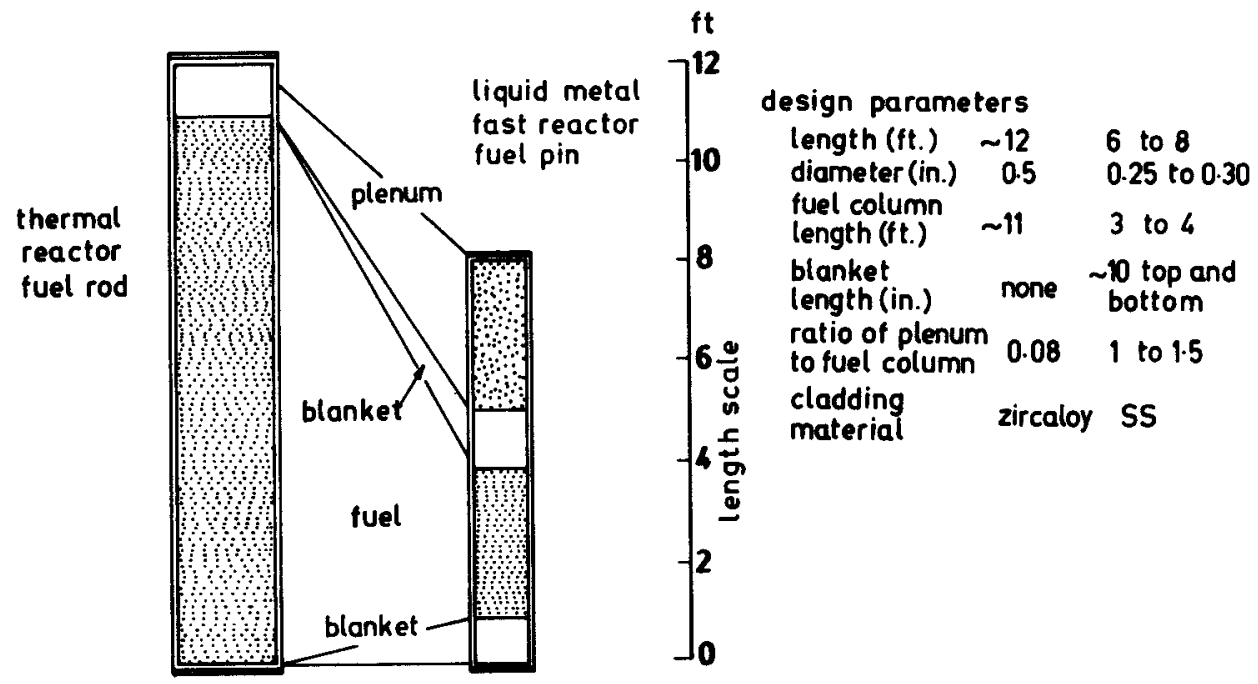

Figure 22. Thermal and fast reactor fuel design parameters. 
hundreds of which constitute the core of a commercial size (1200 MWe) reactor. The pins in a subassembly are held in a regular array by means of regularly spaced grids or the attachment of a spirally wound wire wrap to each pin. A subassembly wrapper envelops the pin bundle, channels the coolant flow over the fuel pin array and provides the structural strength and stiffness of the subassembly. A fuel element subassembly for FBTR is shown in figure 23 (Govindarajan 1985, private communication). Fuel parameters for fast reactors being commissioned or in operation are given in table 9 (Swanson 1987, pp. 122-125).

Fast reactor fuel subassemblies are expected to withstand a rather demanding environment of which the main features are:

(i) Operation in hot sodium resulting in corrosion or erosion of structural materials; experience to date has shown that this is not a major problem.

(ii) Gases are released within the pins from the fission process and cause an increase in internal pressure in the pin. This is allowed for quite simply by providing a plenum space of sufficient volume.

(iii) Internal corrosion of the clad can occur due to volatile fission products like cesium. Experience so far indicates that the effect is not significant at the temperature and heat fluxes specified for pins in commercial reactors.

(iv) Irradiation-induced changes in the properties of structural materials; exposure to high fast neutron fluence $\sim 10^{23} \mathrm{n} / \mathrm{cm}^{2}$ can lead to significant changes in dimensions and mechanical properties. Dealing with the consequences of these is the main challenge for the designer today.

The fundamental performance requirements for a commercial FBR subassembly include adequate spacing between pins to allow liquid metal coolant to pass and remove the heat without overheating the fuel, ease of fuel handling at the end of irradiation despite possible distortions, and low pin failure rates. The main factor which currently limits fast reactor fuel life and fuel burn-up is void swelling. Void swelling produces increases in length and diameter of the wrappers and causes the subassemblies, subjected to gradients in neutron flux and temperature, to bow and interact with its neighbour or core restraint structure. Bowing of subassemblies results from differential void swelling on opposite faces of the wrapper and assumes importance for core edge subassemblies. This bowing can give rise to difficulties in unloading/loading procedures. The best solution to this problem lies in the use of void swelling-resistant materials.

Swelling in the cladding can also limit the achievable burn-ups by causing the pins to extend axially to take up available space within the wrapper and then to buckle, thereby increasing the diameter of the pins. These changes in dimensions will not directly produce failure but may constrict coolant flow resulting in overheating, failure may then ensue by one of several mechanisms, including creep of the cladding under the influence of the fission gap pressure, fuel-clad mechanical interaction, irradiationinduced exhaustion of high temperature ductility.

These considerations indicate the desirability of selecting or developing wrapper materials exhibiting consistently low void swelling and irradiation creep rates. Furthermore, the fuel pin cladding must retain sufficient in-reactor creep strength and ductility to avoid premature failures. Compatibility of wrapper and cladding tube properties with respect to void swelling and irradiation creep are also important to avoid interaction between cladding tubes and wrapper. To accommodate distortions caused by irradiation-induced swelling and creep, additional space or thick ducts and 


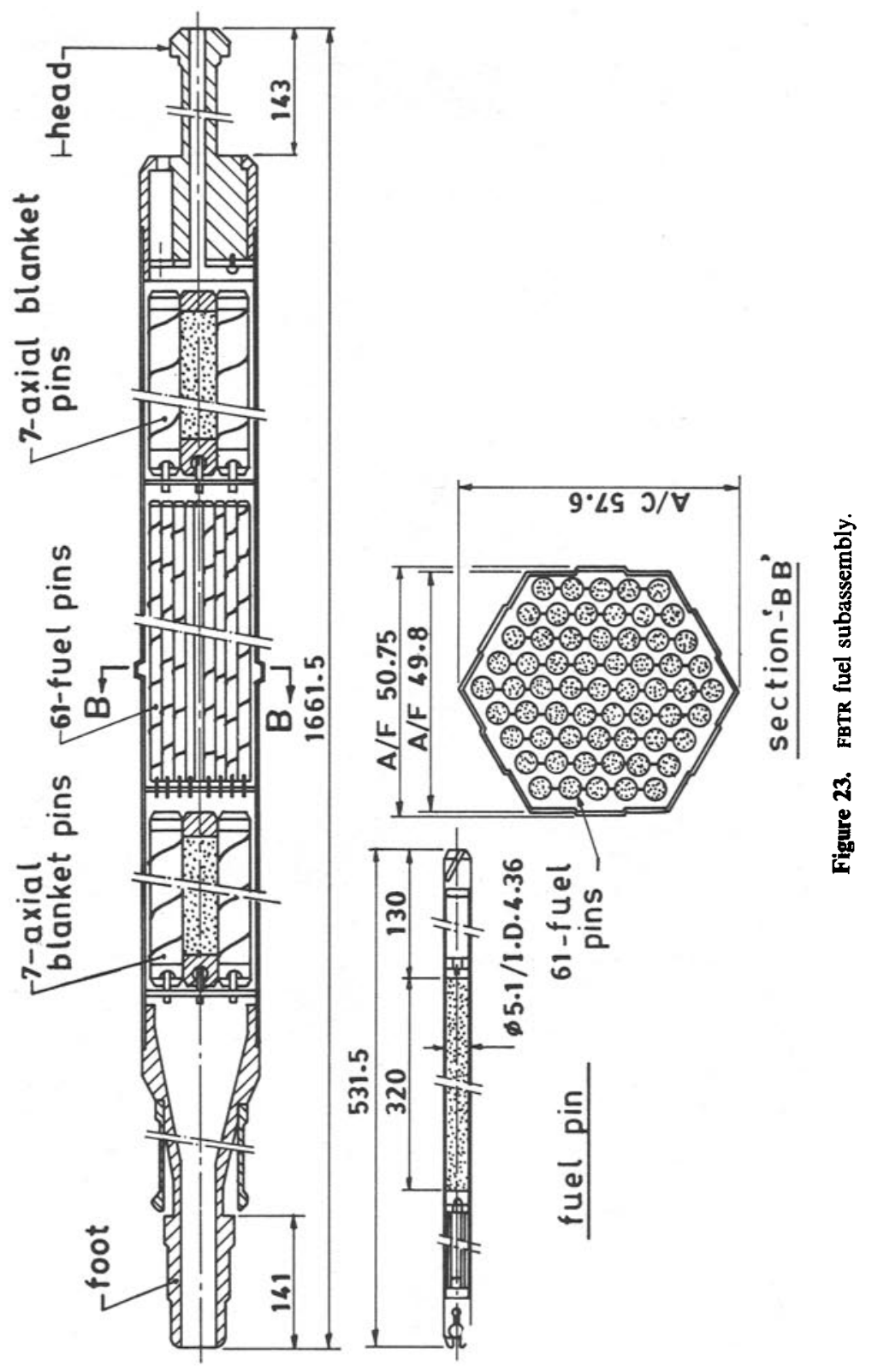




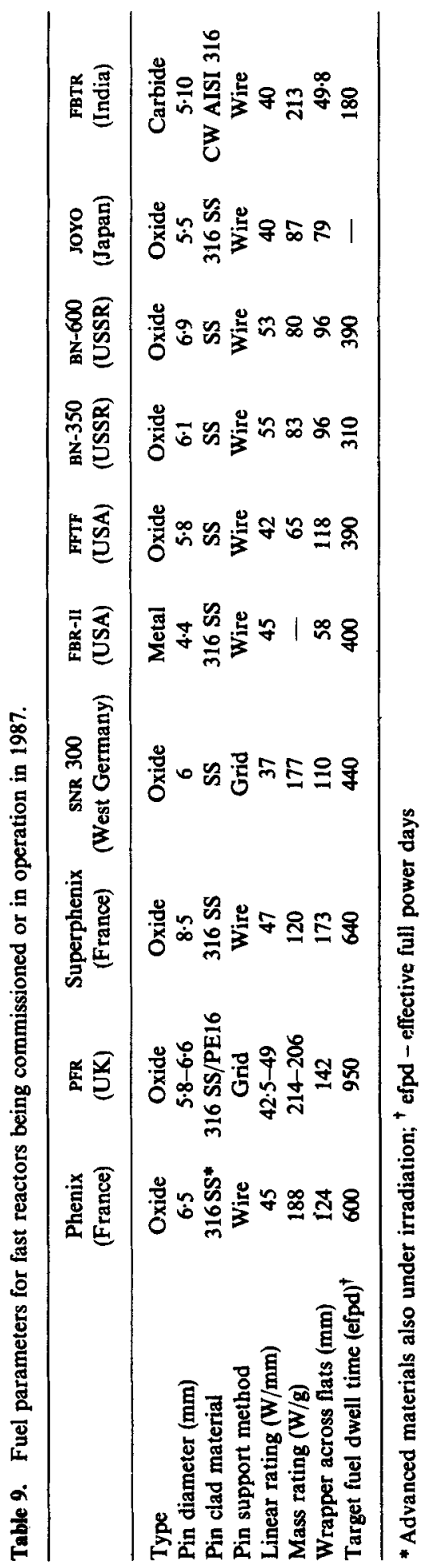


cladding (to reduce stresses) must be provided. This accommodation decreases the fuel volume fraction and degrades breeding performance. This would affect the fuel cycle cost and the overall economy of FBR. The importance of developing materials resistant to irradiation-swelling and creep cannot be overemphasized. Efforts towards this goal have been underway in the last 10-15 years. It has been found that $10-20 \%$ $\mathrm{Cr}$-ferritic/martensitic steels exhibit superior resistance to irradiation-induced void swelling, in-reactor creep and high temperature irradiation-embrittlement as compared to austenitic stainless steels. However, additional development testing of these materials is required before they can be accepted as possible replacements.

\subsection{FBTR fuel}

Alternatives to the almost universal mixed plutonium/uranium oxide fuels are being studied worldwide. They include metallic uranium/plutonium/zirconium, mixed uranium/plutonium carbides and mixed uranium/plutonium nitrides. All claim advantages over mixed oxide fuel as a result of higher metal atom densities (improved breeding), higher thermal conductivities (higher power per pin) and improved safety margins in case of loss of pumping power accidents. However, in all cases the fabrication and reprocessing costs remain as yet uncertain against the increasing body of good experience with oxide fuel.

Plutonium-rich mixed carbide fuel has been chosen for the test reactor, FBTR. The design and specification of the new carbide fuel for FBTR were developed at the IGCAR and BARC. The successful evolution of a fabrication process for this fuel is a significant achievement of the Radiometallurgy Division of BARC. Carbide fuel fabrication is a much more difficult and challenging task involving more fabrication and process control steps than the oxide fuel. Additionally, a strict control of carbon stoichiometry is needed for eliminating the metal phase and keeping the higher carbide phases within acceptable limits. The deviations from stoichiometry have deleterious effects on irradiation behaviour; hypostoichiometry results in the presence of $\mathrm{U}-\mathrm{Pu}$ alloy which causes unacceptable swelling while the presence of higher carbides could lead to major problems with clad carburization in sodium-bonded fuel design.

Plutonium-rich mixed carbide fuel pellets ( $\mathrm{Pu} 66.5$, U 28.5, C 5.0\%) with close control of purity, density, oxygen and nitrogen levels have been fabricated for FBTR by a carbothermic route.

This reactor has been designed to serve as a test facility for the development of advanced fuels and indigenous core structural materials. There is provision to monitor various fuel element performance parameters like temperature, fission gas release, cladding deformation etc. continuously during irradiation. Post-irradiation examination (PIE) forms an important component of the fuel-element development programme. Extensive facilities have been set up at the IGCAR for carrying out metallurgical and chemical PIE of experimental fuel subassemblies. Emphasis is also being placed on modelling studies for prediction of fuel performance and correlation with experimental observation.

\section{Developments in related areas}

Efforts directed towards improvement in fuels and fuel element performance have led 
to significant developments in related areas of materials science and technology. The production of special materials for specific applications in a variety of disciplines is an important spin-off from the developments in materials required for nuclear fuel elements. The production of high purity special materials is linked with the parallel development and availability of powerful analytical techniques which enable the evaluation of products at various stages. Analytical techniques have been developed for determination of impurity concentration at extremely low levels. Improvements in fabrication processes like extrusion, drawing and pilgering have made it possible to produce fuel tubes conforming to stringent nuclear requirements. A very elaborate quality assurance programme has been worked out and a variety of non-destructive testing techniques have been developed to ensure reliability of fuel elements.

\section{Conclusions}

The fuel element is the fundamental building block of the reactor core and the performance of a nuclear reactor is strongly dependent on the quality and reliability of fuel elements. Therefore great care needs to be exercised in the selection of fuel and cladding materials as well as in fuel element fabrication.

Uranium and plutonium have been used for nuclear fuels in the metallic form or in the form of ceramic compounds such as oxides and carbides. The characteristics of nuclear fuels and their suitability for various reactor systems are discussed, and their advantages and disadvantages are highlighted. The general requirements for cladding and other structural fuel element materials and their development have been discussed.

The fuel cycle adopted in India for nuclear power generation is described. Based on extensive R\&D carried out in the Department, integrated flow sheets for the production of nuclear grade $\mathrm{UO}_{2}$ and zircaloy tubes, and their assembly into power reactor fuel elements have been established at the Nuclear Fuel Complex, Hyderabad.

Fuel elements for various types of reactors and their performance characteristics are discussed. Fuel elements for research reactors consist of metallic uranium clad in aluminium. Details of fuel subassembly for the new research reactor, DHRUVA, at the Bhabha Atomic Research Centre, Trombay, have been described. Facilities for fabrication of fuel elements for research reactors have been set up at the Atomic Fuels Division, BARC. Thin-walled collapsible zircaloy cladding and high density sintered natural $\mathrm{UO}_{2}$ pellets have been used in fuel elements in the PHWR while light water reactors employ strong zircaloy cladding and enriched $\mathrm{UO}_{2}$ as the fuel. Factors influencing fuel element performance and various developments to counter the failure mechanisms in fuel elements for water-cooled reactors are discussed in detail. These include hydriding of zirconium alloys, dimensional stability of zircaloy components in irradiation environments, fretting and wear due to flow-induced vibrations, pellet densification under irradiation, cladding corrosion and pellet-cladding interaction.

Gas-cooled reactors are another group of thermal reactors which are welldeveloped. These include carbon dioxide-cooled magnox (with fuel elements consisting of natural uranium metal rods clad in magnesium alloy) and advanced gas-cooled reactors (enriched $\mathrm{UO}_{2}$ pellets clad in stainless steel) and the more recent heliumcooled high temperature reactors (coated $\mathrm{Th}-\mathrm{U}$ carbide or oxide fuel particles dispersed in a graphite matrix). The fuel in high temperature gas-cooled reactors is 
in the form of microspheres of $\mathrm{UO}_{2}$ surrounded by layers of pyrocarbon and silicon carbide.

The importance of FBR for our nuclear power programme is emphasized. Fuel parameters for various fast reactors being commissioned or in operation are compared. Most of the current and planned prototype or commercial fast reactors are fuelled with mixed uranium/plutonium in the form of oxide pellets clad in stainless steel. In view of its advantages with respect to improved breeding performance, mixed uranium-plutonium carbide has been used in our FBTR at Kalpakkam. Achievement of high burn-up is desired for reducing the fuel cycle costs. Current design targets abroad aim at achieving 15 to $20 \%$ burn-up. This is intended to be achieved by the careful selection of structural materials, operating conditions and provision of specific features to cater to the effects of irradiation. Fuel subassemblies in fast reactors have to withstand the very demanding environment of hot flowing sodium and high fast neutron fluence. The high fast neutron environment leads to void swelling, irradiationcreep and helium-embrittlement of fuel element structural materials. These factors limit the fast reactor fuel life, and dealing with the consequences of these induced changes in materials is the main challenge for designers today.

The development of the fabrication technology for the variety of nuclear fuel elements required in the Indian nuclear energy programme, and the organisation of the production activities, in the Metallurgy Group, BARC, Bombay, and at the Nuclear Fuel Complex, Hyderabad, took place under the inspiring leadership of late Professor Brahm Prakash when he was Director, Metallurgy Group, BaRC. Special reference should be made to the pioneering contributions made by $\mathrm{Dr} \mathrm{N}$ Kondal Rao, H C Katiyar, S K Kantan, K Balaramamoorthy, V V Ratnam, K K Sinha, P R Roy, R B Subramanyam, V Chandramouli, Dr T S Krishnan, and their colleagues, in this wide ranging programme.

\section{References}

Cox B 1976 Advances in corrosion science, 5 (eds) M Fontana, R W Staehle (New York: Plenum)

D'Amore M 1987 in Nuclear Technology International (ed.) Neville Geary (London: Sterling)

Das M, Prasad P N 1987 in Fuel and Fuel Management, Introductory Lecture to 30th Batch Training School, delivered at BARC Training School, August

Frost B R T 1969 Proceedings International Symposium Ceramic Nuclear Fuels (Columbus OH: American Ceramic Society)

Frost B R T 1982 in Nuclear fuel elements (New York: Pergamon)

Lawson D S 1987 in Nuclear Technology International (ed.) Neville Geary (London: Sterling)

Matzke Hj 1986 in Science of advanced LMFBR fuels (Amsterdam: North-Holland)

Nibielek H, Heit W 1987 Nuclear Technology International (ed.) Neville Geary (London: Sterling)

Rippon S 1984 Nuclear energy (London: Heinmann)

Simnad M 1971 in Nuclear power reactor, ANS-AEC Monograph (New York: Gordon and Breach)

Simnad M T, Howe J P 1979 in Materials science in energy technology (eds) G G Libowitz, M S Whittinghan (New York: Academic Press)

Strasser A A 1986 Nucl. Eng. Int. 31: 37-40

Sundaram C V 1987 Proc. Indian Natl. Sci. Acad. A53: 1-22

Sundaram C V 1988 in Trans. Indian Inst. Met. 41: 407-431

Swanson K M 1987 in Nuclear Technology International (ed.) Neville Geary (London: Sterling) 